\title{
Integrity of clay till aquitards to DNAPL migration: Assessment using current and emerging characterization tools
}

Fjordbøge, Annika Sidelmann; Janniche, Gry Sander; Jørgensen, Torben H.; Grosen, Bernt; Wealthall, Gary; Christensen, Anders G.; Kerrn-Jespersen, Henriette; Broholm, Mette Martina

\section{Published in:}

Ground Water Monitoring \& Remediation

Link to article, DOI:

10.1111/gwmr.12217

Publication date:

2017

Document Version

Peer reviewed version

Link back to DTU Orbit

Citation (APA):

Fjordbøge, A. S., Janniche, G. S., Jørgensen, T. H., Grosen, B., Wealthall, G., Christensen, A. G., KerrnJespersen, H., \& Broholm, M. M. (2017). Integrity of clay till aquitards to DNAPL migration: Assessment using current and emerging characterization tools. Ground Water Monitoring \& Remediation, 37(3), 45-61. https://doi.org/10.1111/gwmr.12217

\section{General rights}

Copyright and moral rights for the publications made accessible in the public portal are retained by the authors and/or other copyright owners and it is a condition of accessing publications that users recognise and abide by the legal requirements associated with these rights.

- Users may download and print one copy of any publication from the public portal for the purpose of private study or research.

- You may not further distribute the material or use it for any profit-making activity or commercial gain

- You may freely distribute the URL identifying the publication in the public portal 
1 Integrity of clay till aquitards to DNAPL migration: Assessment using current and

2 emerging characterization tools

3 Annika S. Fjordbøge ${ }^{\mathrm{a} *}$, Gry S. Janniche ${ }^{\mathrm{a}, \mathrm{d}}$, Torben H. Jørgensen ${ }^{\mathrm{b}}$, Bernt Grosen ${ }^{\mathrm{b}}$, Gary Wealthall ${ }^{\mathrm{c}}$,

4 Anders G. Christensen ${ }^{\mathrm{d}}$, Henriette Kerrn-Jespersen ${ }^{\mathrm{e}}$, Mette M. Broholm ${ }^{\mathrm{a}}$

$5 \quad{ }^{a}$ Department of Environmental Engineering, Technical University of Denmark, Bygningstorvet,

6 Building 115, 2800 Kgs. Lyngby, Denmark; ${ }^{b}$ COWI, Parallelvej 2, 2800 Kgs. Lyngby, Denmark;

$7 \quad{ }^{c}$ Geosyntec Consultants, 130 Stone Road West, Guelph, Ontario N1G3Z2, Canada; ${ }^{d}$ NIRAS,

8 Sortemosevej 19, 3450 Allerød, Denmark; ${ }^{e}$ Capital Region of Denmark, Kongens Venge 2, 3400

$9 \quad$ Hillerød, Denmark

10 *Corresponding author. Tel.: +45 4525 16 21; fax: +45 459328 50; e-mail address:

11 asfj@env.dtu.dk

\section{Abstract}

14 Field investigations were carried out to determine the occurrence of tetrachloroethene (PCE) combination of tools for the DNAPL characterization was geophysical investigations, Membrane Interface Probe (MIP), core subsampling with quantification of chlorinated solvents, hydrophobic dye test with Sudan IV and Flexible Liner Underground Technologies (FLUTe) NAPL liners with activated carbon felt (FACT). While the occurrence of DNAPL was best determined by quantification of chlorinated solvents in soil samples supported by the hydrophobic dye tests (Sudan IV and NAPL FLUTe), the conceptual understanding of source zone architecture was greatly assisted by the indirect continuous characterization tools. Although mobile or high residual DNAPL $\left(\mathrm{S}_{\mathrm{t}}>1 \%\right)$ only occurred in $11 \%$ of the source zone samples (intact cores), they comprised $86 \%$ of 
the total PCE mass. The data set, and associated data analysis, supported vertical migration of DNAPL through fractures in the upper part of the clay till, horizontal migration along high permeability features around the redox boundary in the clay till, and to some extent vertical migration through the fractures in the reduced part of the clay till aquitard to the underlying limestone aquifer. The aquitard integrity to DNAPL migration was found to be compromised at a thickness of reduced clay till of less than $2 \mathrm{~m}$.

(1)

\section{Introduction}

Dense non-aqueous phase liquids (DNAPLs) such as chlorinated solvents have been widely used and are common groundwater contaminants (Doherty, 2000; Mackay and Cherry, 1989). DNAPL release sites can have significant impacts on groundwater quality as the solubility of the chlorinated solvents may be several orders of magnitude above their regulatory limits. At DNAPL release sites where an aquifer is overlain by a clay aquitard, the groundwater quality in the aquifer will depend on the integrity of the clay aquitard as a barrier to the downwards migration of DNAPL. The low permeability clay aquitard will be associated with a high capillary resistance to DNAPL, which typically results in DNAPL pooling on top of the aquitard (Mercer \& Cohen, 1990). Modelling of dual-porosity media has shown that further spreading of the contaminants may occur by transport of DNAPL in fractures, which are common in many aquitard systems, and in any coarser grained interbeds, and by the interrelated uptake of dissolved contaminants by matrix diffusion (e.g. Esposito \& Thomson, 1999; Kueper \& McWhorter, 1991; Parker et al. 1994, 1997; Reynolds \& Kueper, 2001, 2004; Slough et al., 1999; VanderKwaak \& Sudicky, 1996; Yang et al., 2012). Laboratory studies with both glaciolacustrine clay (O’Hara et al., 2000) and clay till (Jørgensen et al., 1998a) have shown that the fractures may act as rapid conduits for DNAPL migration in a manner that is difficult to predict. The integrity of the aquitard may therefore be compromised by extensive fracture systems. Observations of vertical fractures in Danish clay till show that fractures are common in the oxidized zone of the aquitard and that the likelihood of fracture development 
throughout the entire clay till aquitard increases with decreasing thickness of the aquitard.

Furthermore, the thickness of a less fractured reduced zone and the drainage conditions below the aquitard impact the extent of fractures (Klint et al., 2013). DNAPL migration in these fracture systems will be affected by the matrix diffusion. The dual-porosity media can provide a considerable retention capacity as the mass storage capacity of the matrix is generally much higher than the storage capacity of the fractures (Parker et al., 1997). Hence, a significant volume of DNAPL can be removed from the fractures through dissolution and subsequent diffusion to the aquitard matrix, which may prevent migration of DNAPL through the fractured aquitard. The specific entrapment and dissolution of DNAPLs will be very sensitive to heterogeneities in the media (Poulsen and Kueper, 1992) including variations in the fracture aperture or even small-scale variations in the individual fractures (Esposito \& Thomson, 1999; Yang et al., 2012). Consequently, thorough characterization of DNAPL source zone architecture is essential in relation to management, risk assessment and remediation of sites with dual-porosity media.

The nature of the dual-porosity media, however, makes it difficult to locate the DNAPL and determine the source zone DNAPL architecture. Parker et al. (2004) have made detailed field investigations of the matrix diffusion of trichloroethene (TCE) into a glaciolacustrine clayey silt aquitard with DNAPL pooled on top of the formation. Further studies can be aided by current and emerging characterization tools for direct and indirect DNAPL detection such as: intact core subsampling with depth-discrete VOC quantification (e.g. Griffin \& Watson, 2002; Parker et al., 2003; Rivett et al., 2014); hydrophobic dye test for direct visual confirmation of DNAPL through dye partitioning into the DNAPL e.g. Sudan IV (Cohen et al., 1992; Griffin \& Watson, 2002; Parker et al., 2003; Rivett et al., 2014); FLUTe liners e.g. impregnated with a hydrophobic dye for visual confirmation of DNAPL upon contact with the liner membrane (Broholm et al., 2016; Griffin \& Watson, 2002); Membrane Interface Probe (MIP) for continuous depth-discrete data obtained by volatilization of contaminants, diffusion through the semi-permeable membrane and vapor detection by e.g. Flame Ionization Detector (FID) (Adamson et al., 2014; Griffin \& Watson, 2002; Rivett et 
al., 2014); organic vapor analysis (OVA) screening of soil samples (headspace) or along intact cores with vapor detection by e.g. FID (Griffin \& Watson, 2002); partitioning tracers (aqueous or gaseous) with an affinity to be detained in the DNAPL e.g. in the form of partitioning interwell tracer tests (PITT) (Hartog et al., 2010; Mariner et al., 1999) or soil gas surveys of natural occurring partitioning tracers such as radon, ${ }^{222} \mathrm{Rn}$ (Höhener \& Surbeck, 2004; Schubert et al., 2007; Semprini et al., 2000); Laser-Induced Fluorescence (LIF) with continuous depth-discrete detection of emissions from DNAPL with inherent fluorescent properties e.g. aromatic compounds (D'Affonseca et al., 2008; Kram et al., 2001) or the modified Dye-Enhanced LIF (Dye-LIF) with injection of a hydrophobic dye and subsequent detection of fluorescent changes in the presence of DNAPL e.g. chlorinated solvents (Germain et al., 2014); and the Waterloo profiler with depth-discrete low-purge collection of groundwater samples (direct push) (Parker et al., 2003; Pitkin et al., 1999). Some of these characterization tools have previously been combined in a multiple-lines-of-evidence approach and compared for DNAPL characterization at sandy industrial sites (Griffin \& Watson, 2002; Parker et al., 2003; Rivett et al., 2014). The use of these characterization tools at sites with strongly heterogeneous dual-porosity media is, so far, limited. When assessing the clay till aquitard integrity by a multiple-lines-of-evidence approach with the currently available characterization tools, near-continuous characterization tools are preferable as a high discretization is crucial in DNAPL characterization. The above characterization tools can also be supplemented with newer tools e.g. down-hole FLUTe liners with activated carbon felt (FACT). The purpose of the investigations was to obtain a better conceptual understanding of the DNAPL source zone architecture (incl. chemical mass distribution) in fractured clay till aquitards, thereby improving the assessment of the integrity of the clay till aquitards in terms of aquifer protection and design of remedial actions at DNAPL release sites. The DNAPL source zone architecture was investigated by a combination of current and emerging site investigation methods for direct and indirect documentation of DNAPL, including most of the technologies mentioned above and the novel FLUTe Activated Carbon Technology. The characterization tools have mostly been applied to 
aquifers and detailed studies on DNAPL migration in highly heterogeneous fractured clay tills aquitards are lacking.

\section{Site description}

The field site is a former distribution facility for tetrachloroethene (PCE) and TCE located at

Naverland near Copenhagen, Denmark (Fig. 1). The facility was operational for 18 years (1965-

1983) where an estimated 5000 tons of PCE (subsurface tank, 1.0-2.5 m below ground surface

(bgs)) and 1700 tons of TCE (barrels) were handled. The distribution activities resulted in PCE and TCE DNAPL impacts to the fill and the fractured clay till (vadose zone) from surface spillage of the chlorinated solvents and/or subsurface leakage of PCE from the tank and/or the connection pipe to the southwestern end of the tank. The groundwater table is located approximately $6.5 \mathrm{~m}$ bgs, and the groundwater concentrations also indicate that the underlying fractured limestone aquifer (around 7-8 m bgs) may be impacted by DNAPL.

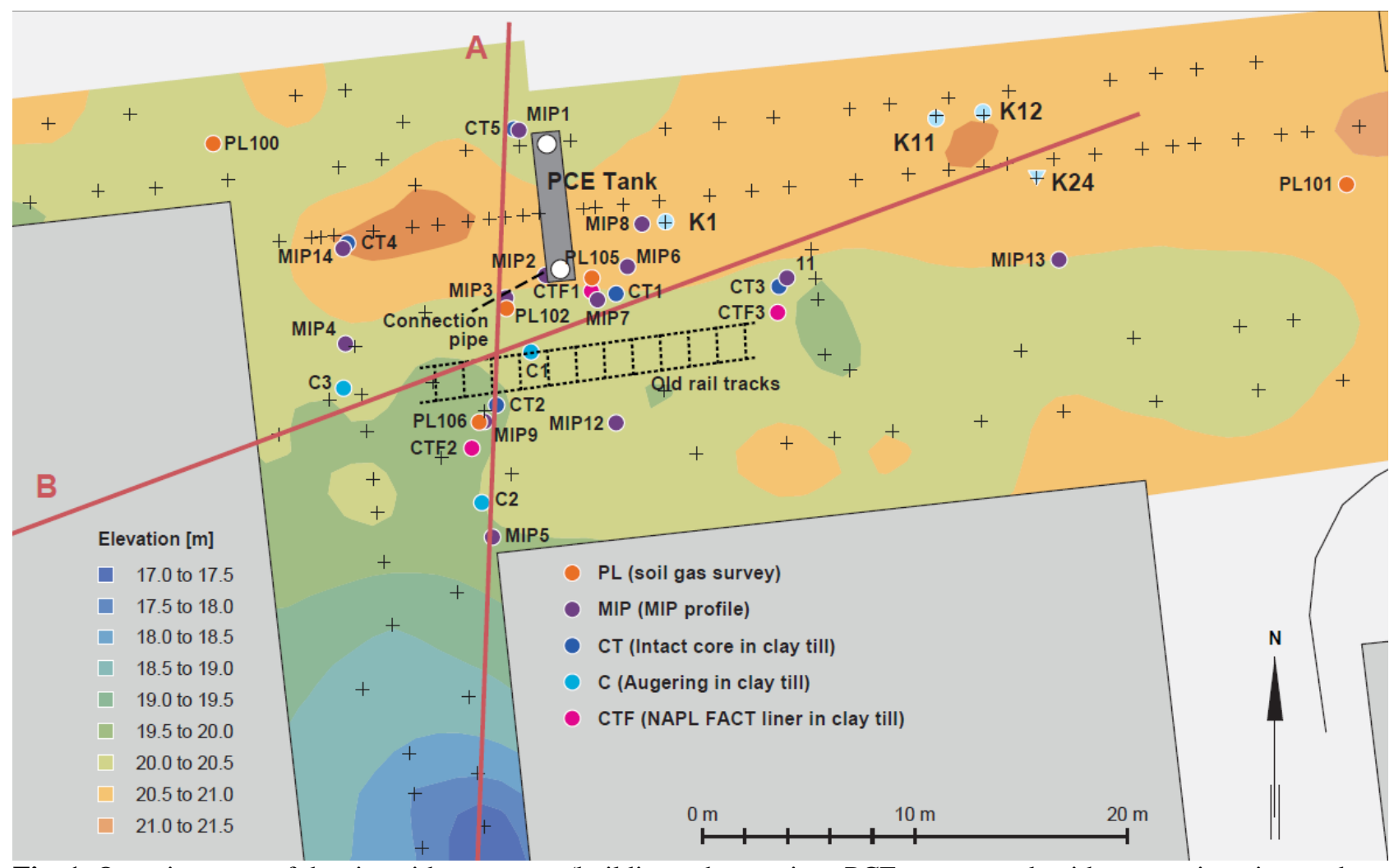

Fig. 1. Overview map of the site with structures (buildings, the previous PCE storage tank with connection pipe, and part of the old rail tracks, north of which the solvents were unloaded), the clay till surface elevation (m above sea level), the 13 MIP profiles (MIP1-9, MIP11-14), the five intact clay till cores (CT1-5), the three auger drillings (C1-3), the 
122 three FACT NAPL FLUTe installations (CTF1-3), and the five soil gas surveys (PL100-102, PL105-106). The red lines 123 indicate part of the geological cross-sections (A and B) in Fig. 2.

124 


\section{Materials and methods}

126

\begin{tabular}{lll}
\hline & Direct methods & Indirect method \\
\hline Continuous & Flexible liners (NAPL FLUTe) & Membrane Interface Probe (Electron Capture \\
& Hydrophobic dye tests (Indigo Blue spray) & Detector (ECD), FID) \\
Point & Hydrophobic dye tests (Sudan IV) & Concentrations on activated carbon (FACT FLUTe) \\
& Direct observations of DNAPL (water or soil) & Organic vapor analysis (OVA) by Photo Ionization \\
& & Detector (PID) (soil samples) \\
& Calculations based on water, soil and/or pore air \\
& concentrations
\end{tabular}

\section{Investigative approach}

Characterization of DNAPL architecture is challenging, and to improve the robustness of the conceptual model, a multiple-lines-of-evidence approach was utilized to obtain data for the conceptual model. The more consistent the different lines of evidence are with a DNAPL architecture scenario, the more plausible the given scenario. The lines of evidence approach combined site history (locations with DNAPL handling and storage), geological characterization (surface geophysics; redox boundary; fracture orientation, inclination, spacing and aperture; and saturation conditions) and a number of direct and indirect characterization tools for detection of DNAPL (Table 1) with different spatial data resolution.

Table 1. Selected characterization methods for direct/indirect and continuous/point determination of DNAPL. 
OVA, hydrophobic dye test) along with installation of FLUTe liners (NAPL, FACT) for method comparison. Since the characterization methods utilize adjacent boreholes ( $1 \pm 0.5 \mathrm{~m}$ spacing), the results will be subject to natural variations in the DNAPL distribution, which is controlled by smallscale features. An overview of the different sampling locations is given in Fig. 1.

\section{Geological characterization}

The transition between different geological layers is based on: surface geophysics, i.e. ground penetrating radar (GPR) with a combination of $100 \mathrm{MHz}$ and $250 \mathrm{MHz}$ antennas and seismic reflection and refraction (SRR) using a Geometrics Geode Ultra-Light Exploration Seismograph; observations from augering and intact coring; electrical conductivity (EC) logging during the MIP profiling; and geophysical borehole logging (mainly gamma) of six existing wells. The surface geophysics were used to determine the transition between fill, clay till and limestone, while the observations from coring and logging were also used to assess the transition between the different clay till units. Furthermore, the coring and augering was used to determine the location of the redox zone in the clay till based on a color shift from oxidized yellowish brown to reduced (olive) gray. The geological characterization was not sufficient for a thorough investigation of fractures; assumptions regarding fractures are, therefore, primarily based on the a priori knowledge of the ground moraine deposits typical in the Copenhagen area gathered through excavations at similar sites within the area (Christiansen et al., 2008; Jørgensen et al., 2003; Klint, 2001). Observations made during clay till core characterization are generally consistent with the a priori knowledge. Textural properties of clay till material at a nearby site (15-20 km) are given by Jørgensen et al. (1998b, 2002).

\section{Membrane Interface Probe (MIP) profiling}

A MIP-6520 heated probe with removable membrane and dipole electrical conductivity array was mounted on a 5400 Geoprobe (direct push drill rig) with a GH41 hydraulic hammer for probe rod advancement. The probe was heated to $120^{\circ} \mathrm{C}$ and the diffused gasses were collected by nitrogen carrier gas (40 mL/min) in a PTFE trunk line. The use of a halogen specific detector (ECD) was 
170

combined with a detector for a broader range of organic compounds (FID). Near-continuous data were collected with a speed of 0.4-0.6 m/min; the data collection was only interrupted by subsampling of the carrier gas for analysis on a calibrated GC-MS (HP 6890). The sensitivity and carry-over was monitored by ongoing response tests (cf. SI for more details). The probe was also equipped with a sensor for continuous EC logging, where clay-rich units are represented by higher EC readings.

\section{Soil gas survey of natural occurring partitioning tracer $\left(\mathbf{R n}^{222}\right)$}

The pore air was collected at 2-3 depths using a GeoProbe to place the probes. Back pressure, the PID value, $\mathrm{CO}_{2}, \mathrm{CH}_{4}$ and $\mathrm{O}_{2}$ were monitored until the soil gas probe was purged (stabilization) (cf. SI for more details). The pore air was analyzed for chlorinated solvents (GC, HP 6890) and $\mathrm{Rn}^{222}$ (scintillation cells, duplicates). Due to analytical issues associated with the chlorinated solvents, the data are only used qualitative to indicate likely DNAPL presence in areas where DNAPL has been confirmed by other methods.

\section{Sampling of the clay till units}

Intact core collection and subsampling

The intact coring was done by the GeoProbe Dual-Tube system (1.5” ID) at five locations. The cores were retrieved in PVC liners (38 mm wide; $1.2 \mathrm{~m}$ long), which were sealed with PVC stoppers and adhesive tape. The samples were stored vertically (same orientation as in the subsurface) at $10^{\circ} \mathrm{C}$ until they were subsampled (within 4 days). The intact cores were initially split in half lengthwise and subsampled in a ventilation hood. One half was utilized for hydrophobic dye test (Indigo Blue), while the other half was subsampled for chlorinated solvents analysis (pentane extraction; 258 samples in total), hydrophobic dye test (Sudan IV; 56 samples in total) and OVA readings (PID; 64 samples in total). Subsampling of the cores was done by small core drills (0.5-1 cm ID) with a plunger. Subsamples were generally collected at high resolution around any observed larger fractures/lenses and/or at a set interval depending on the type of test. After the cores had been 
subsampled for DNAPL characterization, a more meticulous geological assessment was performed for better insight into the small-scale geologic features of the source zone (cf. SI for more details). Augering

Clay till samples were collected with a discretization of $0.5 \mathrm{~m}$ at depths between 1.0-8.0 m bgs at three additional locations (C1-C3) using augering equipment (the geology was documented during the field work). The clay till was sampled for chlorinated solvents analysis (pentane extraction), OVA screening (PID) and occasionally hydrophobic dye tests (Sudan IV). Additionally, certain clay till characteristics (porosity, bulk density, dry matter and water saturation) were determined based on six subsamples collected between 1.5-6.0 m bgs at C1.

\section{Quantitative analysis}

The clay till subsamples were extracted (using pentane) for analysis of chlorinated solvents. A known amount (by weight) of water $(10 \mathrm{~mL})$, clay till $(5 \mathrm{~g})$ and pentane $(5 \mathrm{~mL})$ were added to the extraction vial (40 mL VOA vial). The vial was vigorously shaken (vortex mixer) and placed in a rotation box at $10^{\circ} \mathrm{C}$ until the following day when the pentane was extracted and analyzed by GCMS.

\section{Organic vapor analysis}

The organic vapor was analyzed using a Microtip 10.6 eV Krypton PID lamp calibrated with isobutylene gas. The cores were screened by running a handheld PID along the surface. Samples were collected and transferred to Rilsan ${ }^{\circledR}$ diffusion-proof bags, which were closed with headspace and stored at $4^{\circ} \mathrm{C}$ until the following day. Before the PID analysis of the headspace, the samples were acclimatized to room temperature ( $>4$ hours).

Hydrophobic dye test

Two types of hydrophobic dye test kits from Cheiron Resources Ltd. were used i.e.

OilScreenSoil ${ }^{\circledR}$ (Sudan IV) containing the hydrophobic red dye Sudan IV and a water soluble fluorescent green dye and OilScreenDNAPL-LENS Spray® containing the hydrophobic blue dye Indigo Blue (cf. SI for more details). 


\section{Flexible Liner Underground Technology (FLUTe)}

The FLUTe is a tubular urethane coated nylon liner (Cherry et al., 2007). The liner was installed with GeoProbe (direct push) in three boreholes (CTF1-CTF3) as close as possible (approximately 1 $\mathrm{m})$ to the intact cores collected at CT1-CT3. The inside-out flexible liner was attached to the casing (5.7 cm or 2.25”) and pushed through the subsurface with the GeoProbe. The liner had a polyethylene pipe for air and/or water addition tethered inside the interior bottom of the liner. As the casing was withdrawn the liner was filled with air ( 0.7 bar) to push the liner against the borehole wall. Once the casing was removed the liner was filled with water (4.1 bar) to maintain the interior pressure against the borehole wall. Retraction was done by pulling the tether and inverting the liner. The liner was exposed to the borehole wall for 24 hours before retraction.

The liner was equipped with a NAPL FLUTe dye impregnated membrane. During the inside-out exposure of the liner in the borehole ( 24 hours) the membrane was in contact with the clay till formation. Any direct contact with NAPL in the formation should activate the dye and thereby form visible stains on the membrane. The liner was also equipped with a longitudinal strip of highly porous activated carbon felt, referred to as FACT. During exposure in the borehole, the FACT, contained within a diffusion barrier, was pushed against the clay till formation, which should result in sorption of the contaminant though contact with DNAPL, pore water and/or pore air. After retraction of the liner, the NAPL membrane was inspected on-site by cutting the inverted liner open; the locations of NAPL stains were documented. The FACT was cut in half lengthwise and subsampled in discrete subsections of 2-10 cm. The FACT subsamples were extracted (using pentane) for analysis of chlorinated solvents. A known amount (by weight) of water (10 mL), pentane (3 mL) and (by dimensions) FACT (0.06-0.32 g) were added to the extraction vials (20 mL VOA vials). At the end of the day, the vials were placed in a rotation box at $10^{\circ} \mathrm{C}$ for 84 hours before the pentane was extracted and analyzed on GC-MS.

\section{GC-MS analysis}


The pentane extracts from the clay till sampling and the FACT were analyzed by GC-MS using an

Agilent 7980 gas chromatograph system equipped with an Agilent 5975C electron impact (70 eV)

triple-axis mass-selective detector with a 30 m x 0.25 mm I.D x $1.40 \mu \mathrm{m}$ film thickness ZB-624

\section{Data analysis}

The DNAPL threshold concentration, $\mathrm{C}_{\mathrm{T}}$, of the chlorinated solvents in the clay till above which 253 the presence of DNAPL would be suspected was calculated based on partitioning theory (Feenstra 254 et al., 1991):

$$
C_{T}=\mathrm{S} \cdot \mathrm{x} \frac{K_{d} \rho_{b}+n_{w}+n_{a} K_{H}}{\rho_{b}}
$$

where $\mathrm{S}$ is the solubility of the compound, $\mathrm{x}$ is the molar fraction of the compound, $\mathrm{K}_{\mathrm{d}}$ is the partitioning coefficient between pore water and soil, $\rho_{\mathrm{b}}$ is the bulk density, $\mathrm{n}_{\mathrm{w}}$ is the water-filled 258 porosity, $\mathrm{n}_{\mathrm{a}}$ is the air-filled porosity and $\mathrm{K}_{\mathrm{H}}$ is the dimensionless Henry's law constant.

259 The DNAPL saturation can be given as the saturation of the total porosity, $\mathrm{S}_{\mathrm{t}}$ :

$$
S_{t}=\left(C_{\text {Total }}-C_{T}\right) \frac{\rho_{b}}{\rho_{D N A P L} n_{t}}
$$

261 where $\mathrm{C}_{\text {Total }}$ is the total amount of the chlorinated compound in the soil, $\mathrm{n}_{\mathrm{t}}$ is the total porosity and $\rho_{\text {DNAPL }}$ is the density of the DNAPL.

$$
n_{f}=2 \frac{2 \mathrm{~b}}{2 \mathrm{~B}}
$$

267 where $2 \mathrm{~b}$ is fracture aperture and $2 \mathrm{~B}$ is fracture spacing.

268 Site specific values were obtained for the porosity $\left(\mathrm{n}_{\mathrm{t}}, \mathrm{n}_{\mathrm{w}}, \mathrm{n}_{\mathrm{a}}\right)$, bulk density, $\rho_{\mathrm{b}}$, and dry matter 269 (samples from C1); the average values were $n_{t}$ of $0.27(\sigma=0.01), n_{w}$ of $0.24, n_{a}$ of $0.03, \rho_{b}$ of 1.96 $\mathrm{kg} / \mathrm{L}(\sigma=0.03 \mathrm{~kg} / \mathrm{L})$ and dry matter of $91 \%(\sigma=2 \%)$. The $\mathrm{K}_{\mathrm{d}}$ values used for clay till were 
271 determined at two similar clay till sites within $10 \mathrm{~km}$ of the Naverland site, and the values were 1.37 $272 \mathrm{~L} / \mathrm{kg}$ [0.84-2.45 kg/L] and 0.85 L/kg [0.62-0.96 kg/L] for PCE and TCE, respectively (Lu et al., 273 2011). The solvent densities used were $1.63 \mathrm{~kg} / \mathrm{L}$ and $1.46 \mathrm{~kg} / \mathrm{L}$ and the water solubilities were $2740.00024 \mathrm{~kg} / \mathrm{L}$ and $0.0014 \mathrm{~kg} / \mathrm{L}$ for PCE and TCE, respectively (Broholm \& Feenstra, 1995), while 275 the dimensionless Henry's law constants used were 0.75 and 0.40, respectively (Pankow \& Cherry, 276 1996).

\section{Results and discussion}

279

\section{Site geology}

The geophysics and the drilling/coring at the site showed an overall geology with a vadose zone consisting of a fill layer (0-1 m bgs) and two fractured clay till units (1-7 m bgs), an upper more fractured unit (ML1) and a lower sandier unit (ML2) (Fig. 2). The redox boundary was located around $5.0 \mathrm{~m}$ bgs $(\sigma=0.8 \mathrm{~m})$ with a local depression in the area around CT2, C1 and C3. The EC logging confirms transitions around $2.8 \mathrm{~m}$ bgs (ML1 to ML2) and $4.5 \mathrm{~m}$ bgs (redox transition) (cf. SI, Fig. S1). The local fluctuations in the position of the redox boundary are likely linked to variations in the development of vertical fractures, whereby locally more developed fractures will result in a deeper lying redox boundary. According to Klint et al. (2013), Danish field observations show a medium to high likelihood of fractures throughout the clay till aquitard at sites where the thickness is less than 8-10 m (reduced clay till $<3 \mathrm{~m}$ ). This applies to the Naverland site, where the clay till layer is around $6 \mathrm{~m}$ thick (reduced layer of 1-3 m). 
A)

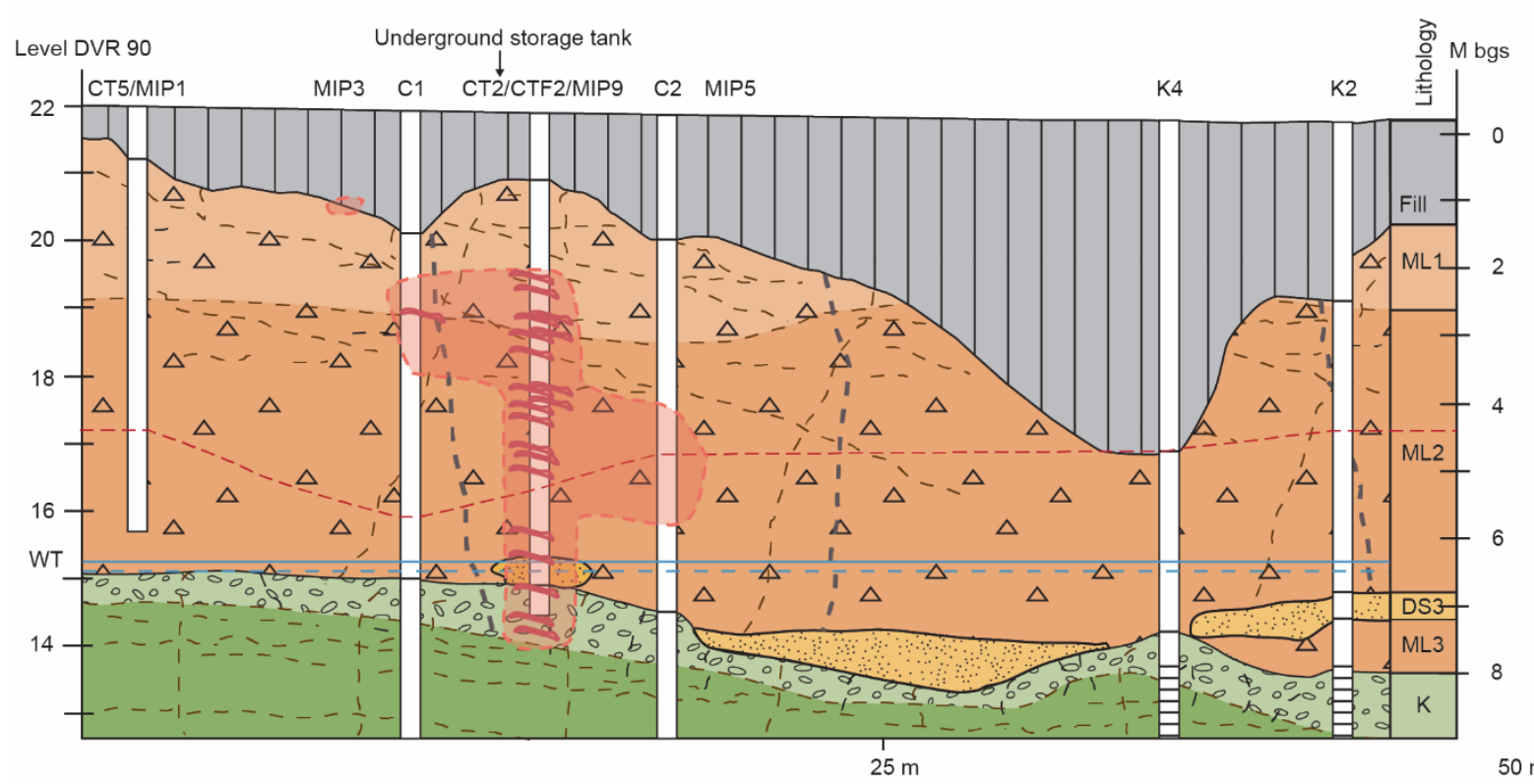

B)

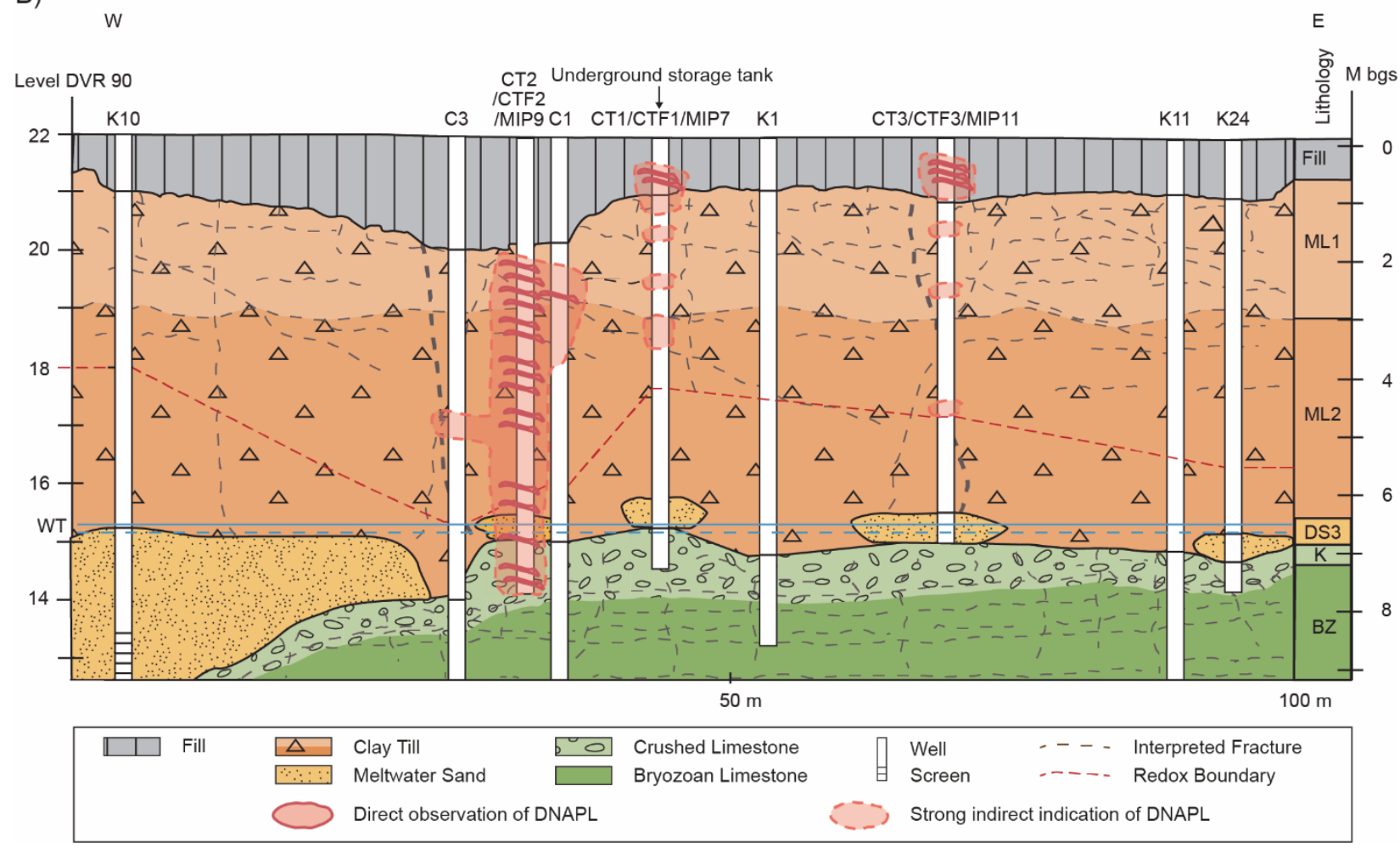

Fig. 2. Conceptual site geology (cf. cross-sections A and B on Fig. 1) with the approximate location of the redox

boundary and direct observations and strong indirect indications of DNAPL. Fractures are interpreted fractures

representing the higher frequency in the upper clay.

The inclination and orientation of the geological surfaces and fractures are of great importance for

understanding the potential migration of DNAPL in the clay aquitard. The geophysics at the site

showed that the surface of the clay till formation was generally dipping towards the S/SW (Fig. 1). 
The glacial deposits in the area are associated with advances of Baltic ice from the southeast (Kjær

301 et al., 2003). The fractures in the clay till generally originate as glacial-tectonic (sub-horizontal

302 shear, conjugating sub-vertical shear and vertical extention) and contraction (freeze-thaw and

303 desiccation) fractures. The vertical extension fractures are oriented in the direction of the ice

304 movement (SE-NW), while the sub-vertical shear fractures are oriented perpendicularly to the ice

305 movement (SW-NE). The shear fractures generally have an inclination dipping in the same

306 direction as ice advancement (Klint, 2001), where the most developed fractures have an inclination

307 dipping towards the SE, while a less developed fracture system has an inclination dipping towards

308 the NW (ice recession and ice advancement, respectively).

309 The contraction fractures have a more irregular orientation and become less frequent with depth

310 (Klint, 2001; McKay et al., 1993). The upper 3.5-5 $\mathrm{m}$ above the redox boundary are expected to be

311 impacted by numerous contraction fractures. Observations showed an average fracture spacing of

312 around $30 \mathrm{~cm}$ in the upper 3-4 $\mathrm{m}$. Fracture spacing has been classified for 13 Danish clay sites

313 (Jørgensen et al., 2003; Klint, 2001). The spacing above the redox boundary is generally 5-30 cm,

314 while it gradually increases below the redox boundary with a spacing of $40-180 \mathrm{~cm}$ at $7 \mathrm{~m}$ bgs

315 (Jørgensen et al., 2003). For Danish sites, clay till fracture apertures of 10-80 $\mu \mathrm{m}$ have been

316 reported (Jørgensen et al., 1998b, 2002), which is similar to values reported for other clay tills (e.g.

317 McKay et al., 1993). An average fracture aperture of $50 \mu \mathrm{m}$ has been reported for clay till

318 (Jørgensen et al., 2002; McKay et al., 1993).

319 Above the groundwater table, the clay till matrix is generally considered to be saturated, while the

320 fracture systems are unsaturated. The water saturation is lower in the upper part of the clay till (67

$321 \%$ at $1.5 \mathrm{~m}$ bgs), and increases to $88 \%(\sigma=2.5 \%)$ at 3.0-5.0 m bgs. The groundwater flow will

322 predominantly be vertical through the larger fractures. The clay till is underlain by a thick bryozoan

323 limestone aquifer, where the transition zone between the clay and the limestone consists of

324 approximately $1 \mathrm{~m}$ of sand, gravel and brecciated limestone. According to Klint et al. (2013), the

325 occurrence of fractures in the clay aquitard is increased if the underlying aquifer offers well-drained 
conditions as the subglacial drainage conditions are a key factor for the deformation mode (ductile or brittle) of basal clay tills. The well-drained B-type basal till (brittle deformation) is more heterogeneous with systematic fractures. A highly transmissive aquifer, like the one at the

329 Naverland site, will thereby increase the likelihood of fractures fully penetrating the clay till unit.

330 Based on the geology at the site, there is a relatively high risk that DNAPL could migrate though

331 (sub-)vertical fractures in the clay till aquitard to the underlying limestone aquifer.

DNAPL migration

While the characterization tools can be used to assist in the horizontal delineation of the DNAPL

DNAPL within the source area for the assessment of the integrity of the fractured clay till aquitard.

Most of the characterization tools were therefore focused on obtaining a vertical delineation of additional locations are included in the SI (Fig. S2).
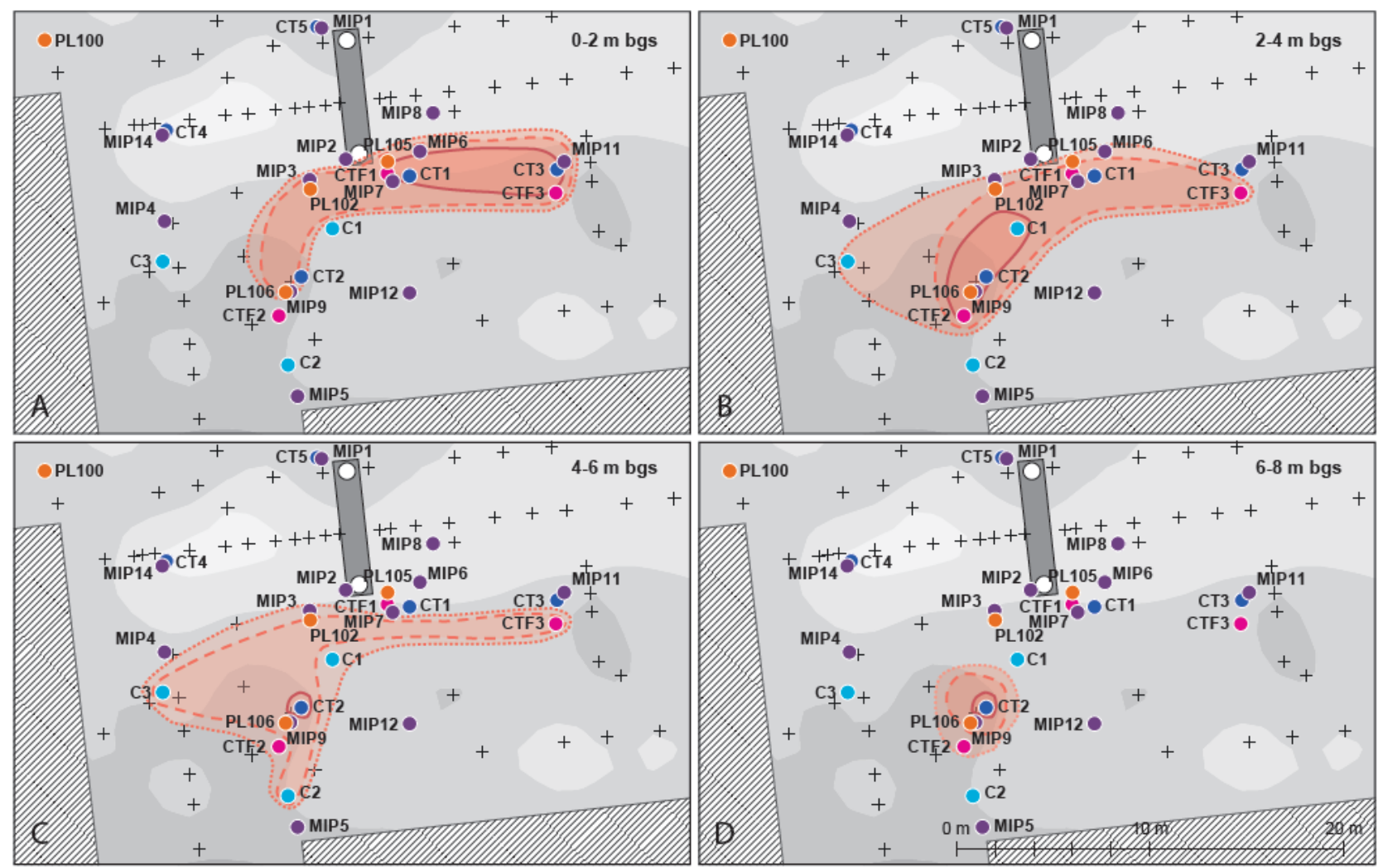

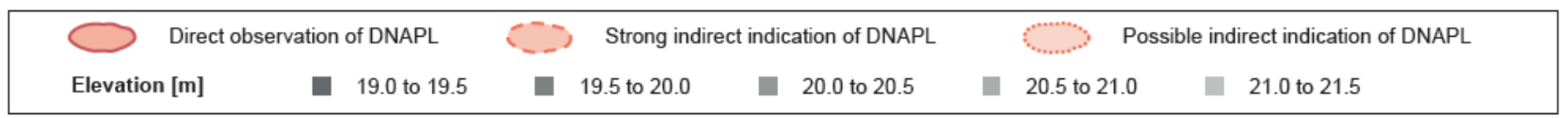


Fig. 3. Delineation of the horizontal DNAPL distribution in the source area in four depth intervals. The red lines

341 indicate: direct observation of DNAPL by dye colorization test i.e. Sudan IV or NAPL FLUTe; strong indirect

342 indication of DNAPL by contaminant concentration ( $\mathrm{S}_{\mathrm{T}}>0 \%$ ), NAPL FLUTe smearing/spotting, high MIP response

343 (FID $\geq 5 \mathrm{~V}$ ), or high soil air concentrations (PID $>4000 \mathrm{ppm}$ ); and possible indirect indication of DNAPL by NAPL

344 FLUTe transparency (increased transparency of line colors through the membrane), medium MIP response $(2.5 \mathrm{~V}<$

345 FID $<5$ V), or medium soil air concentrations (2000 ppm $<$ PID $<4000$ ppm).

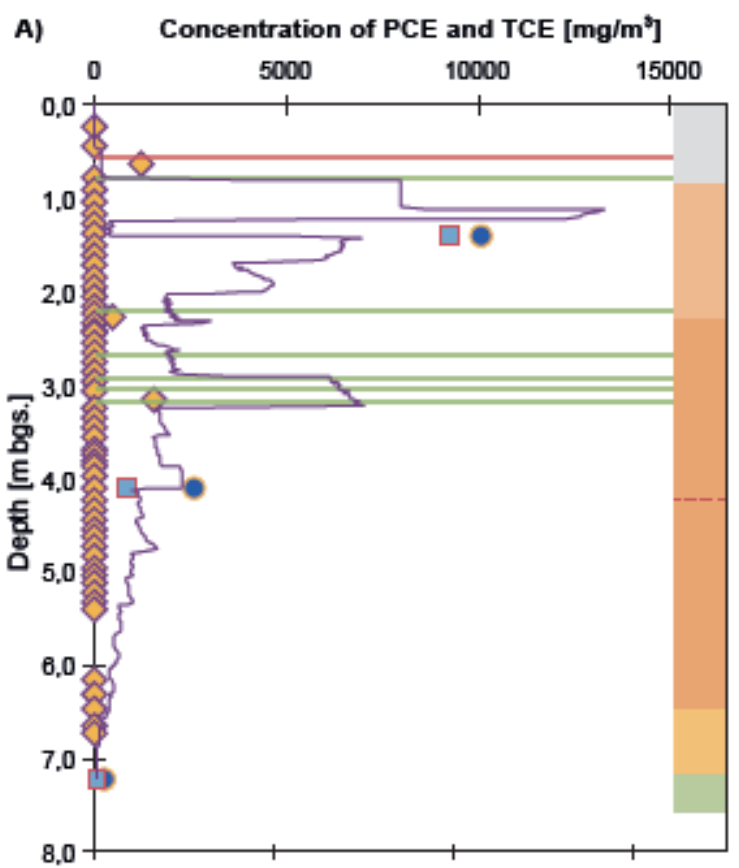

C)

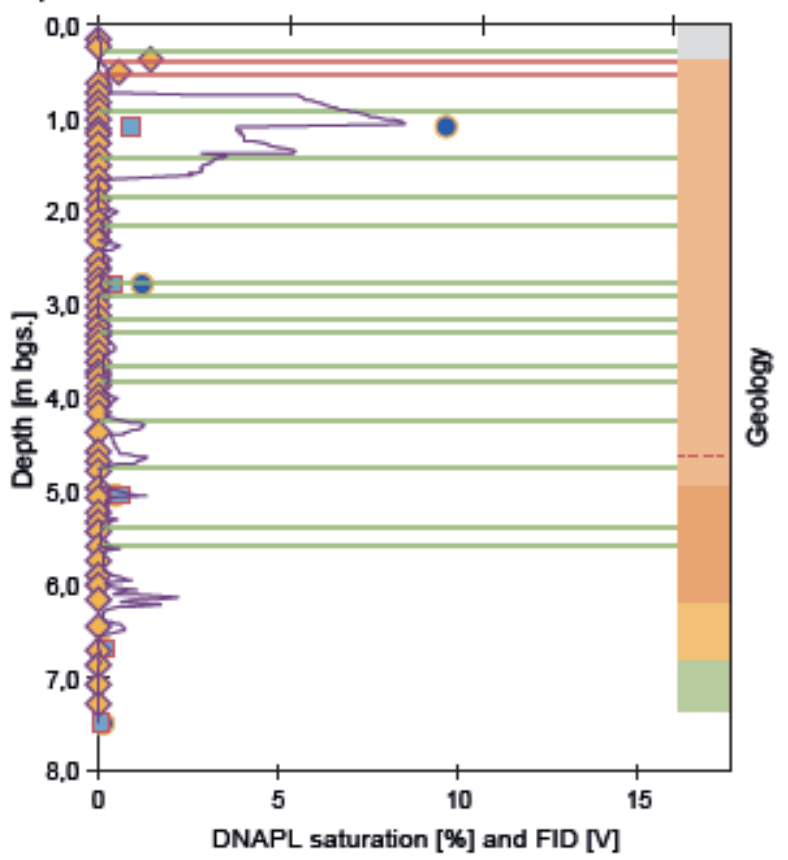

B) Concentration of PCE and TCE $\left[\mathrm{mg} / \mathrm{m}^{\mathrm{*}}\right]$

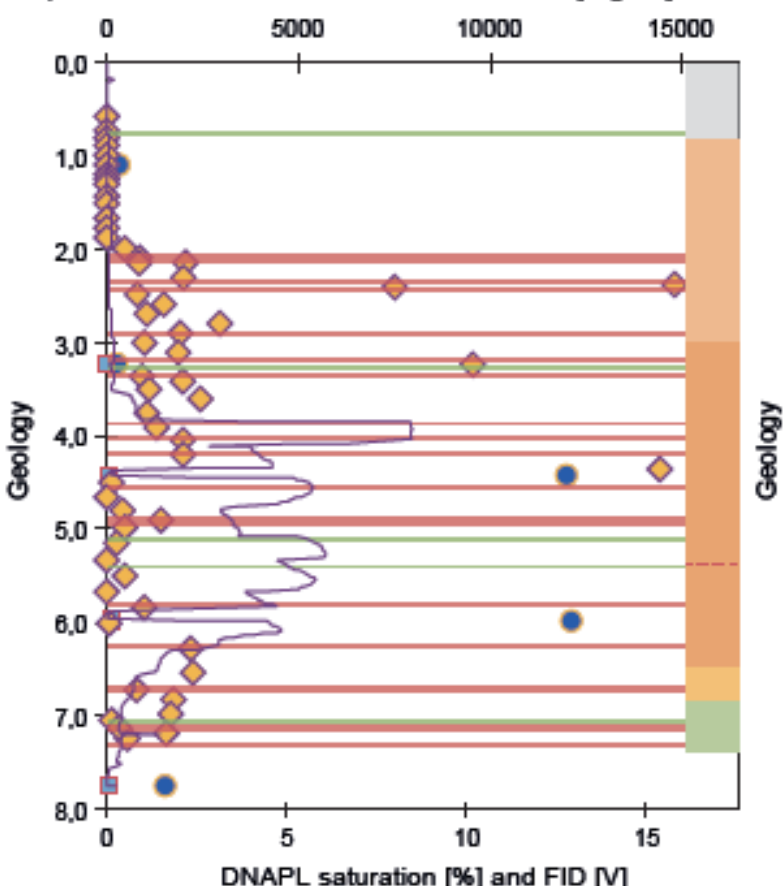

DNAPL saturation [\%] and FID [V]

\begin{tabular}{|c|c|c|c|}
\hline - & PCE & 口 & Fill \\
\hline 口 & TCE & 口 & Upper clay till \\
\hline$\diamond$ & DNAPL saturation & 口 & Lower clay till \\
\hline & FID & 口 & Sand \\
\hline & Negative Sudan (iV) responce & $\square$ & Limestone \\
\hline & Positive Sudan (IV) responce & --- & Redox boundary \\
\hline
\end{tabular}



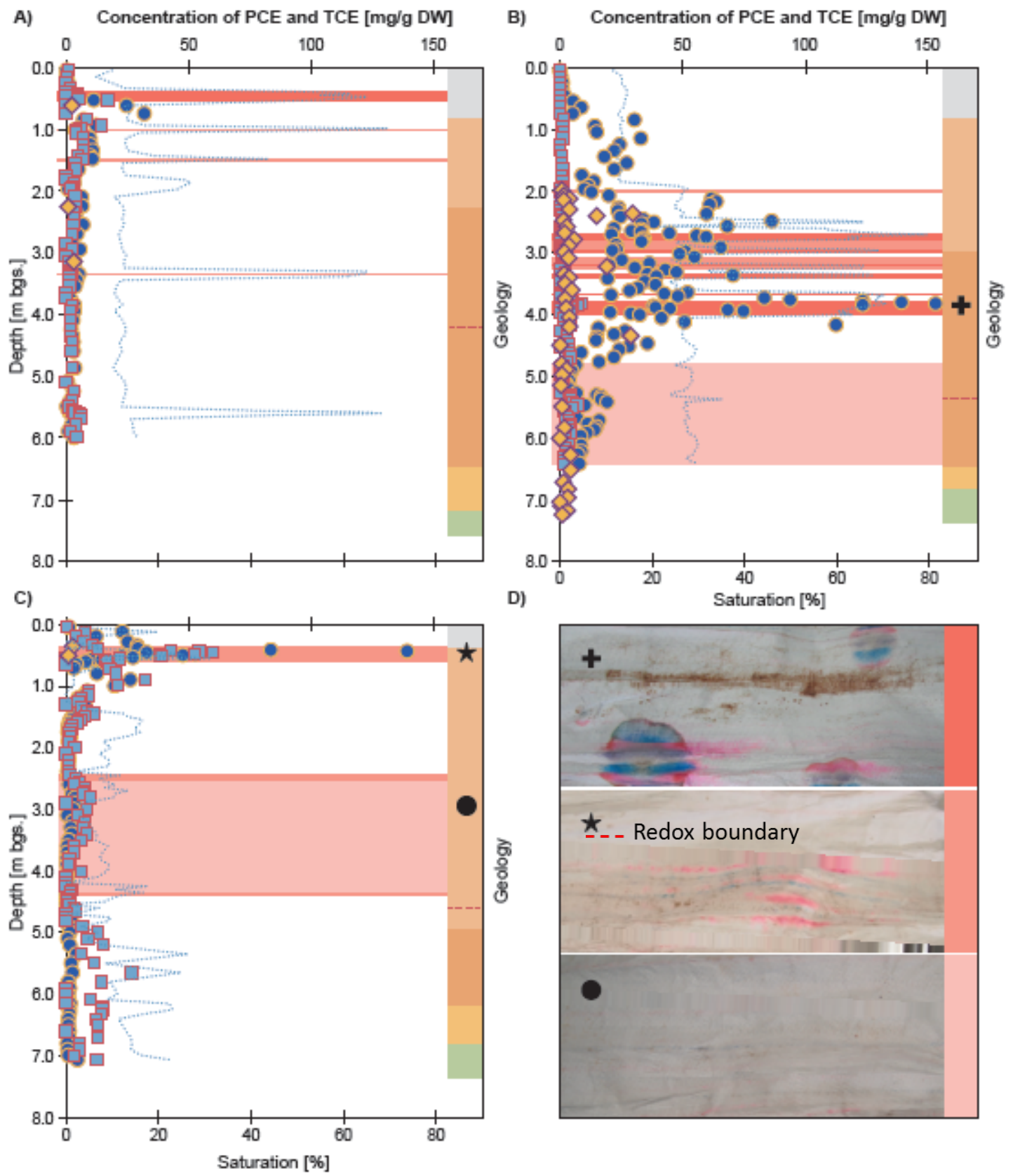

D)

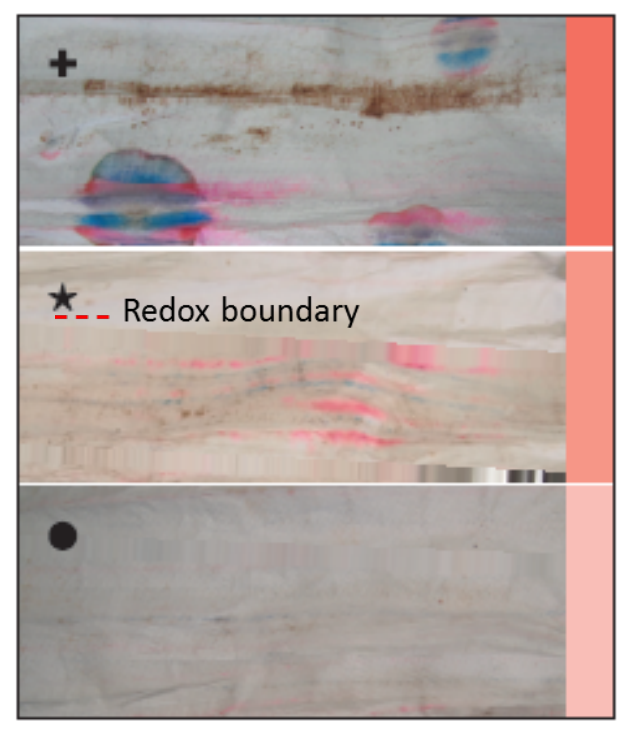

\begin{tabular}{|c|c|c|c|c|c|c|c|}
\hline e & PCE & $\mathbf{\square}$ & DNAPL stain & 回 & Fi & $\square$ & Sand \\
\hline$\square$ & TCE & $\square$ & DNAPL smear/spot & 四 & Upper clay till & $\square$ & Limestone \\
\hline$\diamond$ & $\begin{array}{l}\text { DNAPL saturation } \\
\text { Water saturation }\end{array}$ & 口 & Increased line visibilty & $\square$ & Lower clay till & --- & Redox boundary \\
\hline
\end{tabular}

Fig. 5. DNAPL saturation (\% of total porosity, only $\mathrm{S}_{\mathrm{t}}>0 \%$ is included), water saturation (\%) of the FACT material (not formation), PCE and TCE FACT concentration (mg/g DW) and NAPL FLUTE response comparison. The three

354 pictures indicate the typical extent of staining (staining, smearing and transparency) on the FLUTe NAPL liner at the given color shade. a) CT1 + CTF1; b) CT2 + CTF2; c) CT3 + CTF3. 
Clay till samples

358 The intact core recovery was generally good with an average recovery of $86 \%(\sigma=20 \%)$. The 359 average recovery was affected by a few unsuccessful core recoveries; while the majority of the 360 cores had excellent recovery of more than $95 \%$. The discrete subsampling with quantification of 361 chlorinated solvents was used as a reference for the other methods.

362 The main constituent of the DNAPL was PCE with an average TCE molar fraction of $0.031(\sigma=$ 363 0.001). This is the case for the deeper laying DNAPL in the area southwest of the PCE tank (cf. Fig. 364 3), which likely originates from PCE leakage with TCE as an impurity. Locally, TCE molar 365 fractions were higher (up to 0.49) close to the surface, especially in the area southeast of the PCE 366 tank, where the DNAPL likely originates from spillage of solvents handled at the surface.

367 Based on the average DNAPL composition, the calculated DNAPL threshold concentrations (eq. 368 1) are $317 \mathrm{mg} / \mathrm{kg}$ for PCE [206-545 mg/kg] and $39 \mathrm{mg} / \mathrm{kg}$ for TCE [30-43 mg/kg]. The DNAPL 369 threshold concentration is sensitive to sorption, the given concentration ranges indicate the possible 370 variation in DNAPL threshold concentrations based on the variation found in $\mathrm{K}_{\mathrm{d}}$ values for Danish 371 clay till (Lu et al., 2011). The indicated variations in $\mathrm{K}_{\mathrm{d}}$ values will have a limited effect on the 372 calculated (eq. 2) DNAPL saturations ( $\pm 0.2 \%)$. The threshold concentrations are exceeded at three 373 out of five intact core sampling locations (CT1-CT3) (Fig. 4).

374 The dye tests with Sudan IV for direct identification of DNAPL worked well for determination of 375 PCE (or mixed PCE/TCE) DNAPL (Fig. 4). A color reaction was never observed in adjacent clay 376 till samples containing PCE concentrations less than $250 \mathrm{mg} / \mathrm{kg}$ (below calculated DNAPL 377 threshold), while concentrations of PCE in adjacent clay till samples above $1500 \mathrm{mg} / \mathrm{kg}$ (equal to $378 \quad 0.5 \%$ DNAPL saturation of the total porosity) consistently resulted in coloration (cf. Fig. S4, SI). 379 For the clay till samples with PCE concentrations in the in-between interval (250-1500 mg/kg), 380 variable results were observed. This could be a result of false negatives due to interpretation issues 381 with weak coloration or DNAPL dissolution at lower DNAPL saturations $(<0.5 \%$ of the total 
porosity) and/or the variability in DNAPL saturation at even short distances, whereby the reference concentration in the nearest clay till subsamples is not representative for the actual subsample used for the dye test.

The blue-dye OilScreenDNAPL-LENS Spray ${ }^{\circledR}$ did not result in any visible coloration on the grey/brown clay till cores. This was also the case for cores where DNAPL had been confirmed at the opposite core half using the Sudan IV dye test. Hence, the spray was not a useful tool for DNAPL determination at this clay till site.

The final measurement on the samples from the intact cores and the augering was OVA by PID (cf. Fig. S3 in SI for maximum values). In previous studies with OVA by FID, readings exceeding 1000 ppm (Cohen et al., 1992) or 3000 ppm (Griffin \& Watson, 2002) have been used to infer areas associated with DNAPL (confirmed by other methods). When comparing the PID results of this study with the calculated DNAPL threshold concentrations in samples from approximately the same depth, the PCE concentrations were always above the threshold in the samples where PID > 4000 ppm. PID values > 4000 ppm were also correlated with $90 \%$ of the Sudan IV tests that were positive for DNAPL. The threshold was never exceeded when PID $<1000 \mathrm{ppm}$ and all Sudan IV tests were negative for DNAPL at PID < 1500 ppm (cf. Fig. S5-6, SI). For PID values between 1000-4000 ppm, indications of DNAPL varied; for PID < 3000 ppm only two indications of DNAPL were found, while mixed indications were linked with PID of 3000-4000 ppm. For two of the locations (CT1 and CT3), DNAPL was only directly observed (dye test) at the top of the upper clay till unit with indirect indications of DNAPL in the oxidized clay till. For the third location (CT2), DNAPL was directly observed (dye test) from $2 \mathrm{~m}$ bgs and throughout both clay till units. CT2 is located in the area with a depression in the redox boundary; hence the presence of DNAPL throughout the clay till units may be associated with locally more developed vertical fractures in that area (cf. Site geology section). The DNAPL threshold concentrations were also exceeded for the three less discretized augering locations C1-C3 (cf. Fig. 2), which are all located close to CT2 (3-8 m), with DNAPL saturations of up to $4 \%$ (direct observation of DNAPL by 
Sudan IV), $2 \%$ and $0.5 \%$, respectively. This is consistent with a deeper occurrence of DNAPL in the southwestern direction from the subsurface PCE tank (cf. Fig. 3). Hence, DNAPL spreading may occur in sub-vertical shear fractures with a NE-SW orientation (cf. Site geology section). The data on the DNAPL threshold concentrations are summarized (Fig. 6) with regard to the frequency of occurrence and the mass distribution for each of the three intact coring locations with DNAPL (CT1-3) and for the total area (all five intact coring locations). The grouping of data is inspired by drainable core technique observations by Parker et al. (2003), where $S_{t}<10 \%$ is linked with residual DNAPL (in a sandy aquifer) and on the grouping by Rivett et al. (2014) for a sandy aquifer (no DNAPL if $<\mathrm{C}_{\mathrm{T}}$; trace DNAPL if $\mathrm{S}_{\mathrm{t}}<1 \%$; moderate residual DNAPL if $\mathrm{S}_{\mathrm{t}}=1-10 \%$; high residual DNAPL if $S_{t}=10-20 \%$; and pooled DNAPL if $S_{t}>20 \%$ ). The grouping has been modified to better suit a fractured media. Also, a lower uncertainty is involved with the trace DNAPL group. Hence the data is grouped in: no DNAPL $\left(<\mathrm{C}_{\mathrm{T}}\right)$, trace DNAPL $\left(\mathrm{S}_{\mathrm{t}}<0.2 \%\right)$, moderate residual DNAPL $\left(\mathrm{S}_{\mathrm{t}}=0.2-1 \%\right)$, high residual DNAPL $\left(\mathrm{S}_{\mathrm{t}}=1-2.5 \%\right)$ and mobile DNAPL $\left(\mathrm{S}_{\mathrm{t}}>2.5 \%\right)$

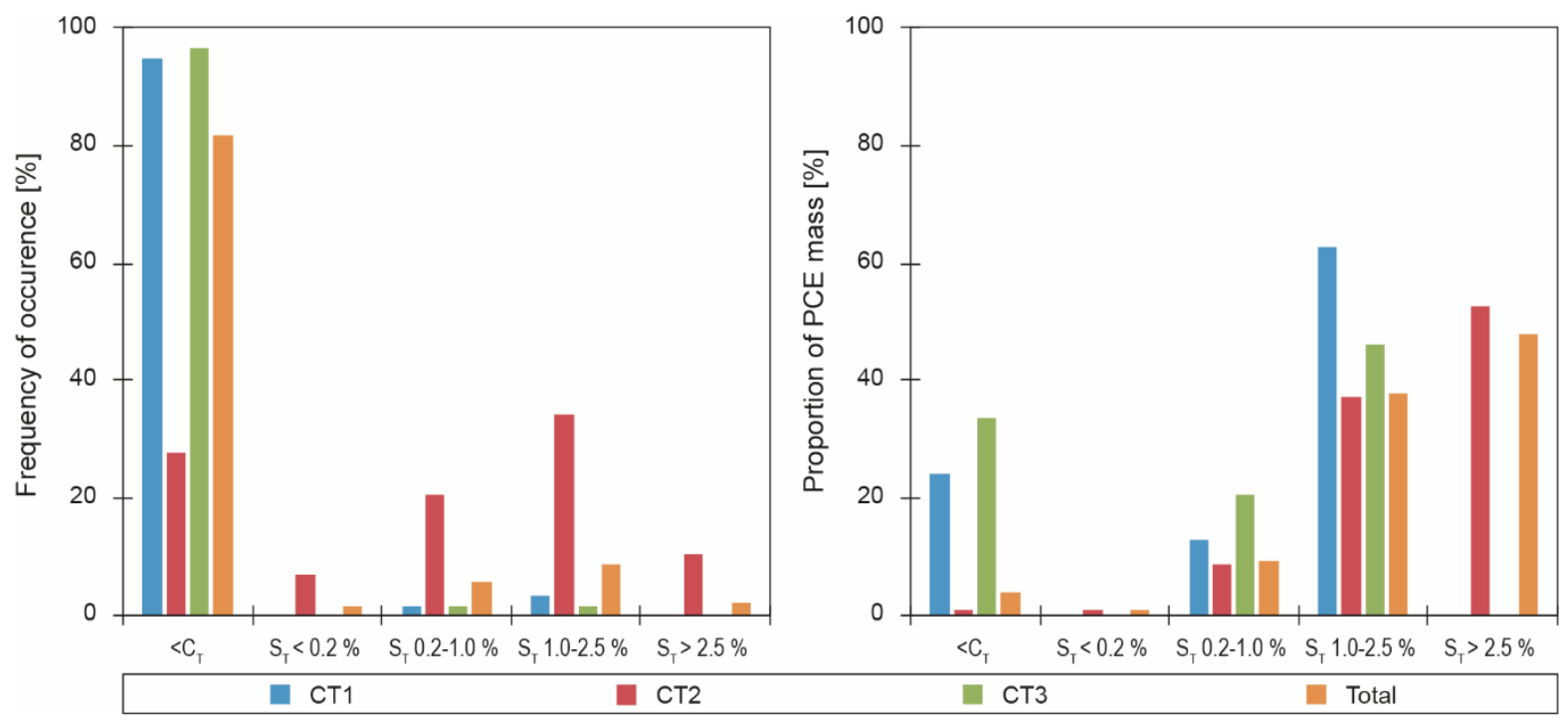

Fig. 6. Frequency of occurrence and the PCE mass distribution for each of the three locations with DNAPL above the threshold concentrations (CT1, CT2 and CT3) and for the total area (all five sampled locations). The data classification is inspired by the one used by Rivett et al. (2014). The classification is: No DNAPL $\left(<\mathrm{C}_{\mathrm{T}}\right)$; trace DNAPL $\left(\mathrm{S}_{\mathrm{t}}<0.2 \%\right)$; moderate residual DNAPL $\left(\mathrm{S}_{\mathrm{t}}=0.2-1 \%\right)$; high residual DNAPL $\left(\mathrm{S}_{\mathrm{t}}=1-2.5 \%\right)$; and mobile DNAPL $\left(\mathrm{S}_{\mathrm{t}}>2.5 \%\right)$. 
The trace DNAPL ( $<0.2 \%)$ class is based on the uncertainty involved with the $K_{d}$ values $( \pm 0.2$ \%). The residual DNAPL classes (moderate at 0.2-1 \% and high at 1-2.5 \%) are based on repeated observations of DNAPL throughout CT2 in this saturation interval (Fig. 4), while large NAPL FLUTe stains are found less frequent (Fig. 5) and therefore linked to mobile DNAPL at a higher saturation (>2.5\%). The divide between the moderate residual DNAPL $(0.2-1 \%)$ and high residual DNAPL (1-2.5 \%) class is somewhat more arbitrary. In CT2 it was found, that the FLUTe transparency (5-6 m bgs) generally occurs at DNAPL saturations below $1 \%$, therefore the division at $1 \%$. The occurrence of mobile DNAPL at significantly lower DNAPL saturations than in a granular media (Parker et al., 2003; Rivett et al., 2014) is ascribed to the fractures where the main DNAPL migration occurs in the dual-porosity media. Considering a realistic range of fracture apertures (10$80 \mu \mathrm{m})$ and fracture spacing $(10-100 \mathrm{~cm})$ the fracture porosity will constitute $<0.01-0.60 \%$ of the total porosity (eq. 3). This would indicate that the fractures are potentially completely saturated at most of the locations with DNAPL. However, since the subsamples, that the calculated DNAPL saturations are based on, represent small volumes, which were often collected at observed fractures, the fracture constitutes a larger part of the total porosity than it would on the overall field scale with larger fracture spacing; e.g. a $50 \mu \mathrm{m}$ fracture would constitute $1.9 \%$ of the total porosity in a $1 \mathrm{~cm}$ wide sample $(\mathrm{n}=0.27)$ or $0.4-3.0 \%$ for the $10-80 \mu \mathrm{m}$ fracture range. This makes it reasonable to assume that mobile DNAPL could occur already at a DNAPL saturation of $2.5 \%$ of the total porosity in the fractured media.

Due to high signal response for halogenated compounds, the ECD was unfortunately prone to 450 overload (>845 V) and subsequent carry-over/drag-down at chlorinated solvent concentrations in 451 the adjacent clay till samples far below $(<10 \%)$ the calculated DNAPL threshold concentration. 452 Thereby the ECD was too sensitive to be used at the DNAPL source zone. This is consistent with 
findings by Adamson et al. (2014), where overload and carry-over/drag-down for the ECD is observed at their "high concentration" area ( $<40 \mathrm{mg} / \mathrm{kg}$ CVOC).

Adamson et al. (2014) also used the less sensitive PID and FID for contaminant characterization in the saturated low permeable zones. However, the FID data were not evaluated beyond initial screening as the response was negligible. In the case of DNAPL, the low FID response to the chlorinated solvents can be a desirable trait making it more suitable as a characterization tool. In our case the FID response was significant, while not exceeding the measuring range ( $<15 \mathrm{~V})$. The FID signal is not halogen specific and the relative response of PCE, TCE and DCE can be expected to be more or less the same with only very small differences due to the slight inhibitory effect on the response from the chlorine atoms (McDermott, 2004); however, the GC-MS subsamples (chlorinated ethenes, chlorinated ethanes and BTEX) confirmed that the response was mainly due to PCE and TCE.

For the locations without DNAPL $(\mathrm{CT} 4-5)$ a reasonable linear correlation $\left(r^{2}=0.750\right)$ was found between the sum of chlorinated solvent concentrations in the clay till samples and the average FID response in the adjacent sampling depths (cf. Fig. S7a, SI). These locations had a maximum concentration of chlorinated solvents (PCE and TCE) of $130 \mathrm{mg} / \mathrm{kg}$ and FID response of $1.2 \mathrm{~V}$. For the locations with DNAPL (CT1-3), no linear correlation could be found ( $\left.\mathrm{r}^{2}<0.01\right)$ (cf. Fig. S7b, SI). This is not surprising as the most significant FID response peaks and the maximum chlorinated solvent concentrations in the adjacent cores are not exactly aligned, indicating a significant spatial variation even within relatively small distances ( $<1 \mathrm{~m})$. Still, the overall trends from CT1-CT5 were captured reasonable well by the nearby MIP7, MIP9, MIP11, MIP14 and MIP1 (cf. Fig. 4 and Fig. $\mathrm{S} 2$ in SI).

While no direct correlation between FID responses and DNAPL saturation could be made, the MIP profiles $(6,7,9,11)$ representing the DNAPL source zone (DNAPL confirmed by dye tests in nearby cores) gave maximum FID responses between $4.8 \mathrm{~V}$ and $14.2 \mathrm{~V}$, whereby FID responses above $5 \mathrm{~V}$ give a strong indication that DNAPL is present at the location. The MIP profiles outside 
479

480

481

482

483

484

485

486

487

488

489

490

491

492

493

494

495

496

497

498

499

500

501

502

503

the DNAPL source area (no DNAPL confirmation or indication in nearby cores) had maximum FID responses of 2.1 V. It is therefore unlikely to find DNAPL if the FID response is consistently below $2.5 \mathrm{~V}$ given response tests of the same magnitude $(15-75 \mathrm{mV}$ response was observed for FID at 5 mg/L PCE solution).

Although no direct correlation was found, the MIP profiling showed significant variations in the FID response and was useful as a screening tool for both vertical and horizontal delineation of the DNAPL area in the low permeable clay till in the vadose zone. The findings were consistent with the historical knowledge on the site. Shallow contamination was found in the eastern part of the area (MIP11, 13) with surface handling of solvents and deeper contamination starting around the redox boundary in the western part of the area (MIP2, 4, 5, 9, 12, 14) where the geological characterization indicates DNAPL would migrate if leaked from the PCE tank. In the central part of the area (MIP3, 6, 7) a combination of the two contaminant profiles was observed.

NAPL FLUTe

A NAPL FLUTe was installed adjacent to each of the three boreholes (CT1-3) where the highest concentrations of chlorinated solvents were detected and the presence of DNAPL was confirmed by hydrophobic dye tests. In CT1 and CT3 direct evidence of DNAPL was found around $0.5 \mathrm{~m}$ bgs (cf. Fig. 4). The presence of DNAPL at this depth was confirmed by staining in CTF1, while a significant smearing of the colored lines was observed in CTF3 (cf. Fig. 5).

In CT2, direct evidence of DNAPL was repeatedly found at 2-7.5 m bgs (Fig. 4). At the depths with the highest DNAPL saturation (2-4 m bgs), staining was found in CTF2 (Fig. 5). At this depth interval, the average DNAPL saturation was $2.9 \%$ of the total porosity, which indicates that mobile DNAPL is present in the fractures at this DNAPL saturation. Contact between the NAPL FLUTe and mobile DNAPL in hydraulically active horizontal fractures is thereby very likely at these depths. At greater depths, where the DNAPL saturation was below $2.5 \%$ of the total porosity, the adjacent NAPL FLUTe liner showed slightly more visible colored lines, but no staining was 
observed. The NAPL FLUTe thereby gives the impression that less DNAPL is present compared to the subsampling of cores at the adjacent location.

The NAPL FLUTe liner is a good tool for direct determination of DNAPL in the borehole. However, the presence of nearby DNAPL without direct contact to the borehole wall will not be detected. Concerns that the presence of residual DNAPL may be overlooked in the staining interpretation have previously been raised (Griffin \& Watson, 2002). The nearby location of residual DNAPL may be indicated by the increased visibility of the colored lines. In initial laboratory studies (Beyer, 2012), it was found that high dissolved concentrations of chlorinated solvents would indeed increase the visibility of the colored lines. An aqueous solution saturated with both PCE and TCE would produce this effect, while a solution saturated only with PCE would not. Unfortunately, the effect will be difficult to interpret and does not give direct evidence of DNAPL.

\section{FACT FLUTe}

The FACT was employed to better delineate the concentrations over depth; direct contact with the DNAPL is not needed. The measured concentrations of PCE and TCE on the FACT are generally in good accordance with the observed staining/coloration trend on the NAPL FLUTe liner (cf. Fig. 5). In CTF1 and CTF3 the highest concentrations on the FACT are measured at 0.4-0.6 m bgs, where staining (CTF1) or smearing (CTF3) of the NAPL FLUTe liner is observed and DNAPL is directly observed in the adjacent core samples (cf. Fig. 4).

Interestingly, while DNAPL saturations ( 1.5 \%) in the adjacent core samples at a depth of around $0.5 \mathrm{~m}$ bgs are comparable for the two locations, the staining on the NAPL FLUTe and the PCE concentration on the FACT were very different (4 times higher in CTF3). The higher FACT concentrations in CTF3 are likely a result of the less saturated conditions; at $0.5 \mathrm{~m}$ bgs the FACT had water saturations of around $60 \%$ and $30 \%$ in CTF1 and CTF3, respectively. Preliminary laboratory results indicated more extensive sorption on the FACT in saturated air than saturated water (Beyer, 2012) as the diffusion coefficient of PCE in air is four orders of magnitude higher 
than in water (Mendoza et al., 1996). Hence, the concentrations in the clay till and on the FACT

531 cannot be directly correlated under variable saturation conditions (cf. Fig. S8).

532 Greatly elevated PCE concentrations were observed on the FACT in CTF2 at 2.0-4.5 m bgs, 533 which correlates well with the depths where staining on the NAPL FLUTe liner was repeatedly 534 observed (Fig. 5) and the depths were the DNAPL saturations in the adjacent core samples were 535 high (Fig. 4). At greater depths (4.8-6.4 m bgs), somewhat elevated PCE concentrations were 536 observed on the FACT, which correlates to the slightly more visible colored lines that were 537 observed on the liner (Fig. 5) and DNAPL saturations in the adjacent core samples were in the 538 residual groupings (Fig. 4). The TCE concentrations on the FACT in CTF2 were generally lower 539 than in the two other liner boreholes, which is consistent with a lower molar fraction of TCE in the 540 deeper contamination as observed in the intact coring.

541 The water saturation of the FACT varied significantly over depth and between the boreholes (Fig. 542 5). The average water saturation of the FACT in the three boreholes was $26 \%(\sigma=21 \%), 37 \%(\sigma$ $543=19 \%)$ and $10 \%(\sigma=7 \%)$ for CTF1, CTF2 and CTF3 respectively. In comparison, the saturation 544 of the less porous clay till formation was around $90 \%$, which correspond to a saturation of around $54525 \%$ given a porosity of 0.97 (FACT) instead of 0.27 (formation). In general, the water saturation 546 of the FACT can be linked to observation of staining on the NAPL FLUTe and to some degree the 547 DNAPL saturation in the adjacent cores. The linkage is most visible in CTF1, where the baseline 548 water saturation on the FACT was around $13 \%$ and six significant peaks of higher water saturation 549 were observed. Four of the five largest peaks ( $>40 \%$ saturation) correspond to the four 550 observations of staining on the NAPL FLUTe, which may correlate to the presence of significant 551 hydraulically active fractures where DNAPL can be transported. These peaks are also relatively 552 well correlated to the depths with the highest FID responses in the adjacent MIP7. Very local 553 occurrence of DNAPL in single fractures is in good accordance with the nature of DNAPL 554 observations in the adjacent CT1 cores, where only one of the three single point observations of 
chlorinated solvents above the DNAPL threshold concentration could be confirmed by adjacent Sudan IV test (5-10 cm spacing).

In CTF2, the baseline water saturation is similar to CTF1 in the upper $2 \mathrm{~m}$, but no peaks in water saturation were observed; no staining on the NAPL FLUTe or DNAPL saturation in the adjacent cores was observed in these upper $2 \mathrm{~m}$. Deeper than $2 \mathrm{~m}$ bgs, the baseline water saturation on the FACT is higher than in the other two locations (around $27 \%$ ), indicating a more water conducting area. At depths below $2 \mathrm{~m}$ bgs, varying degrees of staining on the NAPL FLUTe and DNAPL detection in the adjacent cores were observed. At 2.5-4.0 m bgs, several closely spaced peaks in the water saturation (>60 \%) were observed; those depths correlate well with the observation of staining on the NAPL FLUTe and the highest DNAPL saturations ( $>3 \%)$ in the adjacent cores. This may indicate a locally more fractured area in the clay till with better possibility of DNAPL migration. Below $4 \mathrm{~m}$ bgs, the lack of saturation peaks indicates a less fractured area without horizontal DNAPL migration. The FACT concentrations were still somewhat elevated, while no staining was observed on the NAPL FLUTe, with only a slightly increased visibility of the colored lines. Around $4.5 \mathrm{~m}$ bgs, the DNAPL saturation in the adjacent cores became lower $(<2.5 \%)$, whereby the FACT concentrations likely originated from dissolution of nearby residual DNAPL. In CTF3 the water saturation was generally low without a stable baseline saturation; an increase in the water saturation was observed around the redox boundary at 4-5 m bgs. The highest water saturation (30 \%) was found around $0.5 \mathrm{~m}$ bgs, which was also the location with most visible staining on the NAPL FLUTe and the only observation of DNAPL in the adjacent cores. This may indicate an area with relatively few fractures and a greater importance of pore air diffusion in the matrix.

Although the method only adds qualitative data, the FACT has been valuable for improving the conceptual understanding of DNAPL distribution and mobility in the clay till, which is important for the aquitard integrity assessment. The trends in concentrations on the FACT are generally in good overall accordance with the staining on the NAPL FLUTe liner and the DNAPL saturation in 
581 the adjacent core samples. The variable saturation conditions are seen as a main challenge with 582 regard to linking the FACT concentrations to possible DNAPL presence. Modeling has recently 583 been used for improved interpretation of FACT concentrations under saturated aquifer conditions 584 (Broholm et al., 2016). For clay till aquitards with more uniform saturation conditions (i.e. below 585 the water table) it may also be possible to better correlate contaminant concentrations in the 586 formation and on the FACT.

587 Soil gas survey of natural occurring partitioning tracer $\left(\mathrm{Rn}^{222}\right)$

588 The soil gas survey (radon and chlorinated solvents) was challenged by the high back pressure in 589 the dense clay till deposits, whereby the attempted vertical delineation was not possible. The most 590 useful results were achieved from the shallow sampling points ( $<1.5 \mathrm{~m}$ bgs), where soil gases 591 accumulated in the fill below the asphalt capping and samples were retrieved relatively easy.

592 The results for the source area (PL102, PL105 and PL106) show high PID measurements (>5000 593 ppm) and relatively high concentrations of chlorinated solvents in the soil gases indicating the 594 presence of DNAPL (cf. Table 2). The relative soil gas concentration of TCE was especially high in 595 the eastern part the source area (PL105), which is consistent with surface spillage of chlorinated 596 solvents during handling in that area compared to subsurface leakage of PCE in the western part of 597 the source area. The results from outside the source area (PL100 and PL101) show relatively low 598 PID measurements ( $<100 \mathrm{ppm})$ and relatively low concentrations of chlorinated solvents in the soil gases.

600

601 Table 2. Soil gas survey for chlorinated solvents and $\mathrm{Rn}^{222}$ in shallow sampling points $(<1.5 \mathrm{~m}$ bgs $)$.

\begin{tabular}{|c|c|c|c|c|c|c|c|}
\hline Location & $\begin{array}{l}\text { Depth } \\
\text { (m bgs) }\end{array}$ & $\begin{array}{l}\text { Back } \\
\text { pressure } \\
\text { (mbar) }\end{array}$ & $\begin{array}{l}\text { PID } \\
\text { (ppm) }\end{array}$ & $\begin{array}{l}\text { PCE } \\
\left(\mathrm{mg} / \mathrm{m}^{3}\right)\end{array}$ & $\begin{array}{l}\text { TCE } \\
\left(\mathrm{mg} / \mathrm{m}^{3}\right)\end{array}$ & $\begin{array}{l}\text { cis-1,2- } \\
\text { DCE } \\
\left(\mathrm{mg} / \mathrm{m}^{3}\right)\end{array}$ & $\begin{array}{l}\mathrm{Rn}^{222} \\
\left(\mathrm{kBq} / \mathrm{m}^{3}\right)\end{array}$ \\
\hline PL100 & $1.3-1.5$ & 500 & 61 & 260 & 30 & 0.49 & 130 \\
\hline PL101 & $0.3-1.5$ & 350 & 2.5 & 38 & 0.88 & 0.45 & 17 \\
\hline PL102 1 & $1.1-1.2$ & 450 & 5600 & 830000 & 5100 & 8.6 & 90 \\
\hline PL105² & $1.0-1.1$ & $<50$ & 7100 & 200000 & 25000 & 67 & 30 \\
\hline PL106 2 & $0.9-1.0$ & 100 & $>10000$ & 1600000 & 6800 & $<0.01$ & 220 \\
\hline
\end{tabular}

The chlorinated solvent concentrations are only used qualitatively to indicate likely DNAPL presence in areas where DNAPL has been confirmed by other methods. ${ }^{1}$ Strong indirect indication of DNAPL in the area. ${ }^{2}$ Direct observation of DNAPL in area. 
With the presence of DNAPL in the source area, the $\mathrm{Rn}^{222}$ measurements should be lowere

604 compared to the natural background concentrations by partitioning into the DNAPL. However, the 605 natural variation in $\mathrm{Rn}^{222}$ is high for the clay till $\left(17-130 \mathrm{kBq} / \mathrm{m}^{3}\right)$, whereby the $\mathrm{Rn}^{222}$ concentrations 606 in the DNAPL source area $\left(30-220 \mathrm{kBq} / \mathrm{m}^{3}\right)$ are not statistically lower than the background levels.

607 Based on the combination of poor sampling conditions for soil gas in the dense clay till deposits 608 and the apparent high natural variation in the $\mathrm{Rn}^{222}$ in the heterogeneous clay till deposits, the use of $609 \mathrm{Rn}^{222}$ as a partitioning tracer is not recommended for assessment of DNAPL distribution in clay till.

\section{Method performance and recommendations}

611 Based on the performance of the characterization methods (Table 3), the following lines of 612 evidence approach is suggested to build conceptual understanding at a fractured clay till site. Initial 613 screening by MIP-FID (with GCMS) is done to assist delineation of the DNAPL area and to select

614 locations for in-depth characterization with intact coring and subsequent installation of NAPL

615 FLUTe (with FACT) in the same borehole. Core sub-sampling is done for quantification of contaminant (and DNAPL saturation estimates) and direct evidence of DNAPL by Sudan IV FLUTe is used for direct (continuous) evidence of DNAPL and FACT FLUTe sub-sampling for water content (unsaturated zone) and relative vertical contaminant distribution.

621 Table 3. Performance of the characterization tools and recommendations for use at fractured clay till DNAPL sites.

\begin{tabular}{|c|c|c|}
\hline \multirow{2}{*}{$\begin{array}{l}\text { Method } \\
\text { Intact cores: Concentrations/DNAPL } \\
\text { saturation }\end{array}$} & Performance & Recommendation \\
\hline & $\begin{array}{l}\text { Good performance. } \\
\text { Good core recovery possible in clay } \\
\text { till. }\end{array}$ & $\begin{array}{l}\text { Recommended for quantification o } \\
\text { the contaminants (with DNAPL } \\
\text { threshold concentrations) and } \\
\text { estimation of DNAPL saturation } \\
\text { (dependent on the uncertainty of } \\
\text { site specific parameters). }\end{array}$ \\
\hline \multirow[t]{2}{*}{ Hydrophobic dye test: Sudan IV } & $\begin{array}{l}\text { Good performance. } \\
\text { No false positive DNAPL responses } \\
\text { below the DNAPL threshold } \\
\text { concentration. } \\
\text { Mixed results at DNAPL saturations } \\
\text { of } 0-0.5 \% \text {. }\end{array}$ & $\begin{array}{l}\text { Recommended for direct (point) } \\
\text { evidence of DNAPL in clay till. } \\
\text { May overlook low residual DNAPI } \\
\text { saturations }(<0.5 \%) \text {. }\end{array}$ \\
\hline & $\begin{array}{l}\text { Poor performance. } \\
\text { No observed color response at } \\
\text { locations with confirmed DNAPL. }\end{array}$ & $\begin{array}{l}\text { Not recommended for direct } \\
\text { evidence of DNAPL in clay till. }\end{array}$ \\
\hline OVA by PID (soil samples) & $\begin{array}{l}\text { Low-medium performance. } \\
\text { No DNAPL indications at responses } \\
<1000 \text { ppm, while strong DNAPL }\end{array}$ & $\begin{array}{l}\text { Useful for screening of e.g. core } \\
\text { samples for selection of locations } \\
\text { for further discretization. }\end{array}$ \\
\hline
\end{tabular}




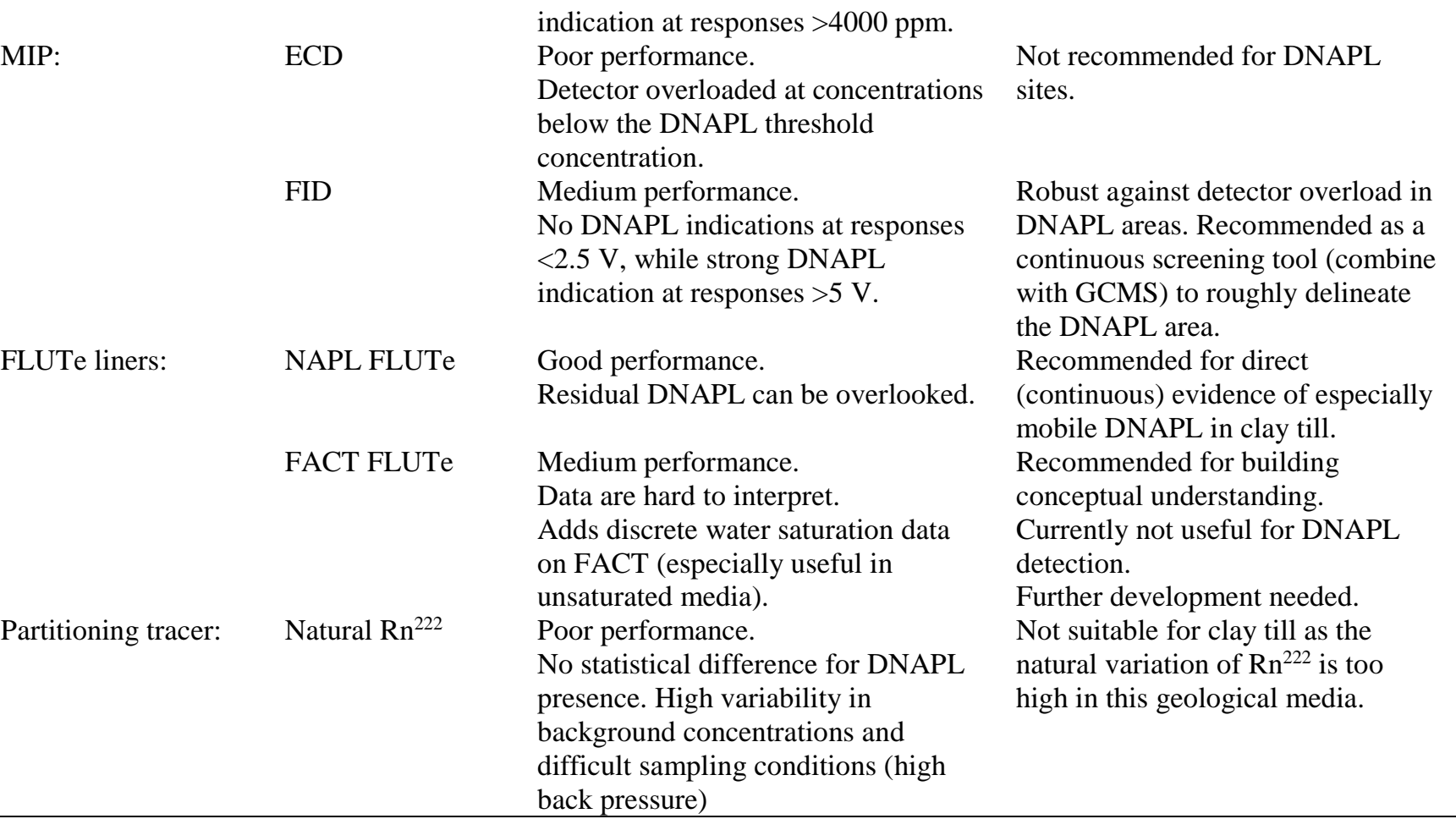

\section{DNAPL source zone architecture and aquitard integrity}

The data set generated supports a division of the source area into an eastern area with a shallower

DNAPL contamination (PCE and TCE) likely resulting from spillage in connection with surface

resulting from subsurface leakage from the PCE tank and/or the connection pipe to the tank (cf. Fig.

3). Most of the characterization methods were suitable for determination of the approximate depth

FACT supported the intact coring in assessing whether the contamination was primarily PCE or a

The DNAPL source zone architecture in the eastern area is represented by DNAPL at the interface 
intact coring and spotting on the NAPL FLUTe coinciding with high water saturation on the FACT

639 (conductive fractures), indications which are likely linked to separate fractures (cf. Fig. 4-5). No

640 indication of DNAPL was observed in the reduced clay till. In the southwestern area, the DNAPL

641 source zone architecture is represented by deeper DNAPL starting around $2 \mathrm{~m}$ bgs (direct

observations). DNAPL migration occurs vertically through fractures in the upper part of the clay till

(direct observations), horizontal migration along fractures and/or other high permeability features above the redox boundary in the clay till (mainly indirect indications), and at one intact coring location continued vertical migration through fractures in the reduced clay till to the underlying aquifer (direct observations). The migration primarily occurs in the southwestern direction from the PCE tank, which is consistent with the fracture orientation typical for the area (cf. Site geology section).

Based on the results, it is expected that extensive vertical DNAPL migration will occur in the upper oxidized part of clay till aquitards, where (unsaturated) fractures are most abundant. Significant horizontal migration will also occur at depths with high densities of horizontal fractures connected to the vertical fractures (e.g. around or above the redox boundary). For the less fractured reduced part of clay till aquitards, the vertical (and horizontal) migration will be more limited and the aquitard integrity to DNAPL migration is largely linked with the thickness of this reduced zone of the clay till aquitards (cf. Fig S14, SI).

At the site, the one location where the aquitard integrity was observed to be compromised is in good agreement with the geological understanding of high risk areas for extensive fracture systems throughout the clay till unit. This area is represented by a depression in the redox boundary (cf. Fig. 2), identified by a bulk color change, which is often linked with locally more developed fracture 660 systems, and the thickness of the reduced clay till is less than $2 \mathrm{~m}$. Based on the FACT FLUTe 661 water saturation in the compromised location, the clay till appears to be more water conducting 662 (fractured) than the locations in the eastern part of the source area. The most extensive fracture system indications coincide with the location of mobile DNAPL saturations ( $>2.5 \%$ encountered at 
2.5-4.5 m bgs) with residual DNAPL saturations (<2.5 \%) in the remaining depths. Hence, the majority of the DNAPL is accumulated in the more extensively fractured clay till above the redox boundary, while smaller amounts of DNAPL have been observed to penetrate vertically into the less fractured reduced clay till and to some extent into the underlying brecciated limestone.

The compromised aquitard integrity towards DNAPL is further supported by comparison of the estimated mass discharge of dissolved PCE ( 2 kg/year) from the DNAPL source area (cf. SI) compared to the mass discharge to the on-going remedial pumping system ( $100 \mathrm{~kg} / \mathrm{year})$ in the limestone aquifer at the site. This would indicate that significant amounts of DNAPL have been discharged to the limestone aquifer.

$$
\text { The geological understanding is important for conceptual development. The fractured clay till in }
$$

the greater Copenhagen area is relatively well-characterized based on excavations in the area. In areas without prior characterization of fractures, local excavations or use of outcrops, gravel pits or similar in the area are highly recommended. For characterization of horizontal fractures (and redox boundary) intact cores are useful, while the FACT FLUTe may give an indication of water conductive fractures in the vadose zone.

\section{Conclusions}

The investigations of the PCE source zone showed that $82 \%$ of the samples from the intact coring did not contain any DNAPL (PCE was below the threshold concentration); those samples only comprised $4 \%$ of the total PCE mass. The majority of the PCE source zone mass was found as mobile DNAPL (St $>2.5 \%$ ) associated with fractures in the clay till (48 \% mass, $2 \%$ occurrence) or as high residual DNAPL ( $\mathrm{St}=1-2.5 \%$ ) in the clay till (38 \% mass, $9 \%$ occurrence). Hence, high resolution site characterization is needed for proper mass estimation and design of remedial actions in the fractured clay till.

No single technique was sufficient for characterization of the DNAPL source zone architecture. However, insight into the source zone architecture in the clay till aquitard was especially assisted by the use of MIP as a continuous qualitative initial screening tool combined with NAPL FACT 
FLUTe and coring with quantitative subsample analysis for establishment of DNAPL threshold concentrations and Sudan IV colorization tests for positive confirmation of DNAPL presence. Surface geophysics with ground penetrating radar (GPR) and seismic reflection and refraction (SRR) combined with geologic information supplemented conceptual understanding of the transport and distribution of DNAPL in the fill and clayey till.

The data set generated from the combined use of the various characterization tools supports the hypothesis that DNAPL released at fractured clay till sites migrated vertically through fractures in the upper oxidized part of the clay till aquitard, horizontally along fractures and/or other high permeability features around the redox boundary, and to some extent vertically through the fractures in the reduced part of the clay till aquitard to the underlying aquifer.

The integrity of clay till aquitards to DNAPL migration is linked with the thickness of the less fractured reduced zone. The vertical migration of DNAPL through the reduced aquitard was only observed where the reduced clay till is less than $2 \mathrm{~m}$ thick, which is consistent with geological studies on high risk areas for fracture development throughout clay till aquitards. The findings on clay till aquitard integrity to DNAPL migration are likely transferable to similar primarily oxidized clay till aquitards of limited thickness.

\section{Acknowledgements}

The presented research was funded by the Capital Region of Denmark through a research collaboration agreement with DTU Environment on "DNAPL source area characterization techniques”. The authors acknowledge the assistance with field and laboratory work, analysis, and graphical assistance by technical staff and students at DTU Environment, especially Bent H. Skov, Jens S. Sørensen, Lisbet Brusendorff, and Monique Beyer, as well as technical staff and colleagues from COWI, NIRAS, FLUTe and Probing. We would also like to acknowledge Dr. Knud Erik S. Klint of the Geological Survey of Denmark and Greenland for support with geological understanding of the Copenhagen area. 


\section{References}

Adamson, D.T., Chapman, S., Mahler, N., Newell, C., Parker, B., Pitkin, S., Rossi, M., Singletary,

M. 2014. Membrane Interface Probe Protocol for Contaminants in Low-Permeability Zones. Groundwater, 52 (4), 550-565.

Beyer, M. 2012. DNAPL characterization in clayey till \& chalk by FACT (FLUTe Activated

Carbon Technique). MSc Thesis, Department of Environmental Engineering, Technical University of Denmark.

Broholm, K., Feenstra, S. 1995. Laboratory measurements of the aqueous solubility of mixtures of chlorinated solvents. Environ. Toxicol. Chem., 14 (1): 9-15.

Broholm, M.M, Janniche, G.S., Mosthaf, K., Fjordbøge, A.S., Binning, P.J., Christensen, A.G.,

Grosen, B., Jørgensen, T.H., Keller, C., Wealthall, G., Kerrn-Jespersen, H. 2016. Characterization of Chlorinated Solvent Contamination in Limestone Using Innovative FLUTe ${ }^{\circledR}$ Technologies in Combination with Other Methods in a Line of Evidence Approach. J. Contam. Hydrol., 189, 68-85.

730 Cherry, J.A., Parker, B., Keller, C. 2007. A new depth-discrete multilevel monitoring approach 731 for fractured rock. Ground Water Monit. R., 27 (2): 57-70.

Christiansen, C.M., Riis, C., Christensen, S.B., Broholm, M.M., Christensen, A.G., Klint, K.E.S.,

Hydrol., 102, 120-139. 
Doherty, R.E., 2000. A history of the production and use of carbon tetrachloride,

741

742

tetrachloroethylene, trichloroethylene and 1,1,1-trichloroethane in the United States: Part 1 historical background; carbon tetrachloride and tetrachloroethylene. J. Environ. Forensics 1, 69-81. Erto, A., Lancia, A., Musmarra, D. 2011. A modelling analysis of PCE/TCE mixture adsorption based on Ideal Adsorbed Solution Theory. Sep. Purif. Technol., 80, 140-147.

Esposito, S.J., Thomson, N.R. 1999. Two-phase flow and transport in a single fracture-porous medium system. J. Contam. Hydrol., 37, 319-341.

Feenstra, S., Mackay, D.M., Cherry, J.A. 1991. A method for assessing residual NAPL based on organic chemical concentrations in soil samples. Ground Water Monit. R. 11, 128-136.

Germain, R.W.St., Einarson, M.D., Fure, A., Chapman, S., Parker, B. 2014. Dye based laserinduced fluorescence sensing of chlorinated solvent DNAPLs. Conference proceedings, paper 1-14, $3^{\text {rd }}$ International Symposium on Cone Penetration Testing, May 12-14, 2014, Las Vegas, NV. Griffin, T.W., Watson, K.W. 2002. A Comparison of Field Techniques for Confirming Dense Nonaqueous Phase Liquids. Ground Water Monit. R., 22(2), 48-59.

Hartog, N., Cho, J., Parker, B.L., Annable, M.D. 2010. Characterization of a heterogeneous DNAPL source zone in the Borden aquifer using partitioning and interfacial tracers: Residual morphologies and background sorption. J. Contam. Hydrol., 115, 79-89.

Höhener, P., Surbeck, H. 2004. Radon-222 as a Tracer for Nonaqueous Phase Liquid in the Vadose Zone: Experiments and Analytical Model. Vadose Zone J., 3, 1276-1285. Jørgensen, P.R., Broholm, K., Sonnenborg, T.O., Arvin, E. 1998a. DNAPL transport through macroporous, clayey till columns. Ground Water, 36(4), 651-660.

Jørgensen, P.R., Hoffmann, M., Kistrup, J.P., Bryde, C., Bossi, R., Villholth, K.G. 2002.

Preferential flow and pesticide transport in a clay-rich till: Field, laboratory, and modeling analysis. Water Resour. Res., 38 (11): 1246.

Jørgensen, P.R., Klint, K.E.S., Kistrup, J.P. 2003. Monitoring Well Interception with Fractures in Clayey till. Ground Water, 41 (6): 772-779. 
Jørgensen, P.R., McKay, L.D., Spliid, N.H. 1998b. Evaluation of chloride and pesticide transport

767 in a fractured clayey till using large undisturbed columns and numerical modeling. Water Resour.

768 Res., 34 (4): 539-553.

769 Kjær, K.H., Houmark-Nielsen, M., Richardt, N. 2003. Ice-flow patterns and dispersal of erratics 770 at the southwestern margin of the last Scandinavian Ice Sheet: signature of palaeo-ice streams.

771 Boreas, 32, 130-148.

772 Klint, K.E.S. 2001. Fractures in glacigene diamict deposits: Origin and distribution. PhD 773 dissertation, Geological Institute, University of Copenhagen, Denmark.

774 Klint, K.E.S., Nilsson, B., Troldborg, L., Jakobsen, P.R. 2013. A poly morphological landform 775 approach for hydrogeological applications in heterogeneous glacial sediments. Hydrogeol. J., 21, 776 1247-1264.

777 Kram, M.L., Lieberman, S.H., Fee, J., Keller, A.A. 2001. Use of LIF for Real-Time In-Situ Mixed 778 NAPL Source Zone Detection. Ground Water Monit. R., 67-76.

779 Kueper, B.H., McWhorter, D.B. 1991. The Behavior of Dense, Nonaqueous Phase Liquids in 780 Fractured Clay and Rock. Ground Water, 29 (5), 716-728.

781 Lu, C., Bjerg, P.L., Zhang, F., Broholm, M.M. 2011. Sorption of chlorinated solvents and 782 degradation products on natural clayey tills. Chemosphere, 83, 1467-1474.

783 Mackay, D.M., Cherry, J.A., 1989. Groundwater contamination: pump-and-treat remediation. 784 Environ. Sci. Technol., 23 (6), 630-636.

785 Mariner, P.E., Jin, M., Studer, J.E., Pope, G.A. 1999. The First Vadose Zone Partitioning 786 Interwell Tracer Test for Nonaqueous Phase Liquid and Water Residual. Environ. Sci. Technol., 33, $787 \quad 2825-2828$.

788 McDermott, H.J. 2004. Air Monitoring for Toxic Exposures. $2^{\text {nd }}$ ed., John Wiley \& Sons, Inc., 789 Hoboken, New Jersey.

790 McKay, L.D., Cherry, J.A., Gillham, R.W. 1993. Field Experiments in a Fractured Clay Till. 1. 791 Hydraulic Conductivity and Fracture Aperture. Water Resour. Res., 29 (4): 1149-1162. 
Mendoza, C.A., Johnson, R.L., Gillham, R.W. 1996. Vapor Migration in the Vadose Zone. In

793 Pankow, J.F., Cherry, J.A. 1996. Dense Chlorinated Solvents and other DNAPLs in Groundwater.

794 Waterloo Press, Portland, OR, USA.

795 Mercer, J.W., Cohen, R.M., 1990. A Review of Immiscible Fluids in the Subsurface: Properties, 796 Models, Characterization and Remediation. J. Contam. Hydrol., 6, 107-163.

797 O'Hara, S.K., Parker, B.L., Jørgensen, P.R., Cherry, J.A. 2000. Trichloroethene DNAPL flow and 798 mass distribution in naturally fractured clay: Evidence of aperture variability. Water Resour. Res., 799 36(1), 135-147.

800 Pankow, J.F., Cherry, J.A. 1996. Dense Chlorinated Solvents and other DNAPLs in Groundwater. 801 Waterloo Press, Portland, OR, USA.

802 Parker, B.L., Cherry, J.A., Chapman, S.W. 2004. Field study of TCE diffusion profiles below 803 DNAPL to assess aquitard integrity. J. Contam. Hydrol., 74, 197-230.

804 Parker, B.L., Cherry, J.A., Chapman, S.W., Guilbeault, M.A. 2003. Review and Analysis of 805 Chlorinated Solvent Dense Nonaqueous Phase Liquid Distributions in Five Sandy Aquifers. Vadose 806 Zone J., 2, 116-137.

807 Parker, B.L., Gillham, R.W., Cherry, J.A. 1994. Diffusive Disappearance of Immiscible-Phase 808 Organic Liquids in Fractured Geologic Media. Ground Water, 32(5), 805-820.

809 Parker, B.L., McWhorter, D.B., Cherry, J.A. 1997. Diffusive Loss of Non-Aqueous Phase 810 Organic Solvents from Idealized Fracture Networks in Geologic Media. Groundwater, 35(6), 1077_ 8111088.

812 Pitkin, S.E., Cherry, J.A., Ingleton, R.A., Broholm, M. 1999. Field Demonstrations Using the 813 Waterloo Ground Water Profiler. Ground Water Monit. R., 19 (2), 122-131.

814 Poulsen, M.M.; Kueper, B.H. 1992. A Field Experiment To Study the Behavior of 815 Tetrachloroethylene in Unsaturated Porous Media. Environ. Sci. Technol., 26(5), 889-895.

816 Reynolds, D.A., Kueper, B.H. 2001. Multiphase flow and transport in fractured clay/sand 817 sequences. J. Contam. Hydrol. 51, 41-62. 
Reynolds, D.A., Kueper, B.H. 2004. Multiphase flow and transport through fractured

819 heterogeneous porous media. J. Contam. Hydrol. 71, 89-110.

820 Rivett, M.O., Dearden, R.A., Wealthall, G.P. 2014. Architecture, persistence and dissolution of a 82120 to 45 year old trichloroethene DNAPL source zone. J. Contam. Hydrol., 170, 95-115.

822 Schubert, M., Paschke, A., Lau, S., Geyer, W., Knöller, K. 2007. Radon as a naturally occurring 823 tracer for the assessment of residual NAPL contamination of aquifers. Environ. Pollut., 145, 920824927.

825 Semprini, L., Hopkins, O.S., Tasker, B.R. 2000. Laboratory, Field and Modeling Studies of 826 Radon-222 as a Natural Tracer for Monitoring NAPL Contamination. Transport Porous Med., 38, $827 \quad 223-240$.

828 Slough, K.J.; Sudicky, E.A., Forsyth, P.A. 1999. Numerical simulation of multiphase flow and 829 phase partitioning in discretely fractured geologic media. J. Contam. Hydrol., 40, 107-136.

830 VanderKwaak, J.E., Sudicky, E.A. 1996. Dissolution of non-aqueous-phase liquids and aqueous831 phase contaminant transport in discretely fractured porous media. J. Contam. Hydrol., 23, 45-68. 832 Winslow, S.D.; Pepich, B.V.; Martin, J.J.; Hallberg, G.R.; Munch, D.J.; Frebis, C.P.; Hedrick, 833 E.J.; Krop, R.A. 2006. Statistical procedures for determination and verification of minimum 834 reporting levels for drinking water methods. Environ. Sci. Technol., 40, 281-288.

835 Yang, Z., Niemi, A., Fagerlund, F., Illangasekare, T. 2012. Effects of single-fracture aperture 836 statistics on entrapment, dissolution and source depletion behavior of dense non-aqueous phase 837 liquids. J. Contam. Hydrol., 133, 1-16. 